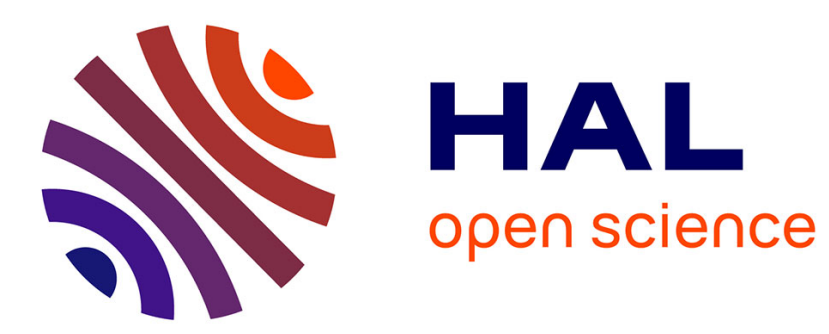

\title{
Cell Migration with Multiple Pseudopodia: Temporal and Spatial Sensing Models
}

\author{
Rachele Allena
}

\section{To cite this version:}

Rachele Allena. Cell Migration with Multiple Pseudopodia: Temporal and Spatial Sensing Models. Bulletin of Mathematical Biology, 2013, 75 (2), pp.288-316. 10.1007/s11538-012-9806-1 . hal01066818

\section{HAL Id: hal-01066818 https://hal.science/hal-01066818}

Submitted on 22 Sep 2014

HAL is a multi-disciplinary open access archive for the deposit and dissemination of scientific research documents, whether they are published or not. The documents may come from teaching and research institutions in France or abroad, or from public or private research centers.
L'archive ouverte pluridisciplinaire HAL, est destinée au dépôt et à la diffusion de documents scientifiques de niveau recherche, publiés ou non, émanant des établissements d'enseignement et de recherche français ou étrangers, des laboratoires publics ou privés. 


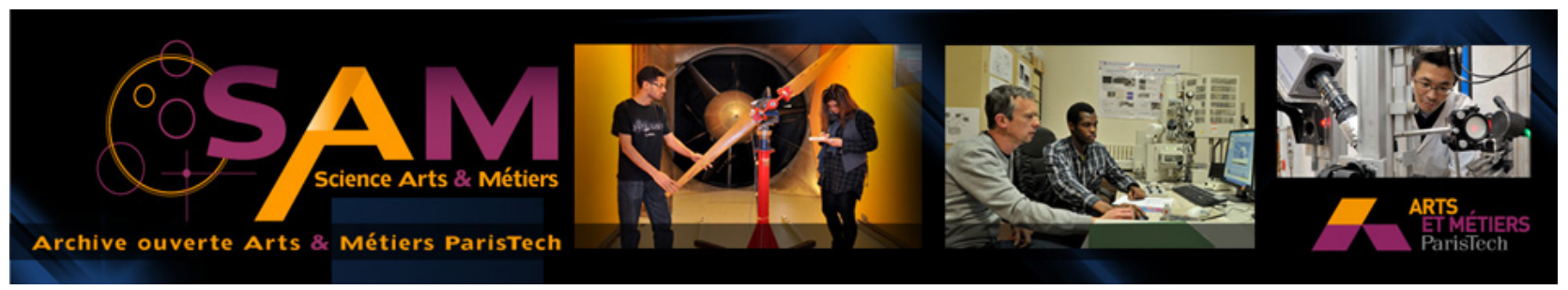

Science Arts \& Métiers (SAM)

is an open access repository that collects the work of Arts et Métiers ParisTech researchers and makes it freely available over the web where possible.

This is an author-deposited version published in: http://sam.ensam.eu

Handle ID: .http://hdl.handle.net/10985/8580

\section{To cite this version :}

Rachele ALLENA - Cell Migration with Multiple Pseudopodia : Temporal and Spatial Sensing Models - Bulletin of Mathematical Biology - Vol. 75, n², p.288-316 - 2013 


\title{
Cell Migration with Multiple Pseudopodia: Temporal and Spatial Sensing Models
}

\author{
Rachele Allena
}

\begin{abstract}
Cell migration triggered by pseudopodia (or "false feet") is the most used method of locomotion. A 3D finite element model of a cell migrating over a 2D substrate is proposed, with a particular focus on the mechanical aspects of the biological phenomenon. The decomposition of the deformation gradient is used to reproduce the cyclic phases of protrusion and contraction of the cell, which are tightly synchronized with the adhesion forces at the back and at the front of the cell, respectively. First, a steady active deformation is considered to show the ability of the cell to simultaneously initiate multiple pseudopodia. Here, randomness is considered as a key aspect, which controls both the direction and the amplitude of the false feet. Second, the migration process is described through two different strategies: the temporal and the spatial sensing models. In the temporal model, the cell "sniffs" the surroundings by extending several pseudopodia and only the one that receives a positive input will become the new leading edge, while the others retract. In the spatial model instead, the cell senses the external sources at different spots of the membrane and only protrudes one pseudopod in the direction of the most attractive one.
\end{abstract}

Keywords Cell migration · Pseudopodia $\cdot$ Computational mechanics $\cdot$ Temporal and spatial model

\section{Introduction}

Many biological phenomena such as embryonic development, wound healing, and immune responses require the orchestrated movement of cells in particular direc-

R. Allena $(\bowtie)$

Arts et Metiers ParisTech, LBM, 151 bd de l'hopital, 75013 Paris, France

e-mail: rachele.allena@ensam.eu 
tions and to specific locations. Errors during these processes may have serious consequences like vascular diseases, tumorogenesis, or metastasis. Nowadays, it is still unclear how exactly cell motility occurs. Therefore, a complete understanding of the mechanisms governing cell migration may lead to the development of novel therapeutic strategies for controlling, for example, invasive tumor cells.

\subsection{Pseudopodia Characteristics}

The most primitive and most used type of locomotion is the one occurring with the support of pseudopodia (or "false feet"), which are a temporary and spontaneous projection of the cytoplasm that form at random sites of the cell's surface by structural reorganization of the actin-myosin network.

The protrusion and the contraction of the pseudopodia are triggered by the polymerization of actin gels (Borisy and Svitkina 2000) and the depolymerization of actin-myosin motors, respectively (Jay et al. 1995; Merkel et al. 2000). Pseudopodia are essential for cell movement since they determine the trajectory, the direction, and the speed of the cell. Also, adjacent cells may coordinate pseudopodia extensions to contribute to collective cell migration (Van Haastert 2010) or contact guidance (Weijer 2009).

There is a considerable variability in size, shape, structure, and mode of working of pseudopodia, on the basis of which they can be grouped into three main categories as follows:

(1) lobopodia: these are blunt relatively short or finger-like, rarely branched pseudopodia;

(2) lamellipodia: these are broad and flat appendages mainly made of cytoplasm;

(3) filipodia: these are rod-like and filamentous extensions often with rounded ends.

Pseudopodia formation is triggered by different types of external signals: chemicals (chemotaxis) (Hoeller and Kay 2007; Weiner 2002) or temperature (thermotaxis) gradients, electric fields (Bahat and Eisenbach 2006; Zhao 2009), or surface heterogeneity (durotaxis). Such external cues may then control the time and the position at the cell boundary where the pseudopod will form, but growth time and length of the pseudopodia are instead independent properties of the false feet (Andrew and Insall 2007; Bosgraaf and Van Haastert 2009a; Karsenti 2008). In order to elucidate how the cell senses the external attractants, two models are generally used. In the temporal sensing model, the cell "sniffs" the surroundings by extending different pseudopodia and only the one that receives a positive input will become the new leading edge (Gerish et al. 1974). In the spatial sensing model instead, the cell senses at different points along the membrane the chemical gradient or the simultaneous external signals introduced in its environment. As a result, only one pseudopod is formed on the side that corresponds to the higher concentration of chemoattractant or in the direction of the most attractive signal. In this case, the cell adopts a polarized shape, with one false foot and a tail (Zigmond et al. 1981).

It has been shown that from an energetical point of view the pseudopodia are more likely to extend perpendicular to the cell membrane (Mogilner and Oster 1996). Therefore, when migration occurs in chemotactic gradients, pseudopodia do not bend 
in the direction of the gradient. To move toward a gradient, the cell needs to develop further pseudopodia at the side closest to the gradient. Additionally, chemotaxis properly occurs when the cell presents a smooth ellipsoid shape. Cells with very irregular shapes show, in fact, poor chemotaxis since pseudopodia form in many different directions (Van Haastert and Bosgraaf 2009).

In general, cells may extend the pseudopodia in two different ways (Andrew and Insall 2007): either by splitting an existing pseudopod or by extending the membrane from areas of the cells not previously active (often referred to as "lateral" or de novo pseudopodia because they appear at the side and in the rear of the cell, Bosgraaf and Van Haastert 2009a). In the first case, few ruffles appear at the base of the existing pseudopod that successively becomes a major pseudopod to which the cell body flows (one way split). Rarely, such a division leads to two equivalent extensions resulting in a Y-shape, one of which can remain active while the other retracts. In the second case, the new pseudopodia start as very lean protrusions that dilate as soon as they include the cell body. Previous studies have shown that the angle between two splitting pseudopodia is approximately $55^{\circ}$ and that very often a split to the right is followed by a split to the left and vice versa, which leads to a zig-zag trajectory (Bosgraaf and Van Haastert 2009a). On the contrary, pseudopodia that form de novo may protrude in any direction without any preference relative to the left or right previous or next pseudopod, which induces a random trajectory.

As it has been observed (Gail and Boone 1970; Patlak 1953; Potel and Mackay 1979), the cell tends to robustly preserve the orientation of motion under perturbations of the external signal. Thus, it migrates with persistence in a given direction and the persistence time depends on the ratio of splitting and formation of new pseudopodia. Weak chemical gradients do not significantly affect the frequency, the dimensions, and the lifetime of the pseudopodia, which mostly follow a self-organization (Andrew and Insall 2007; Bosgraaf and Van Haastert 2009a). The external signals have then three main consequences on the cell behavior:

(1) selective retraction: the cell usually migrates using only one pseudopod at the time. Thus, in the presence of more than one false foot, they all retract but the one which is the best oriented toward the attractant;

(2) oriented extension: in general, more pseudopodia are initialized in the direction of the external cue, which results then in the formation of successive pseudopodia that may be closer or farther according to the position of the cue;

(3) suppression of de novo pseudopodia by which the persistence time is increased.

\subsection{Experimental and Numerical Approaches}

From an experimental point of view, two different strategies have been used in the last decades to better understand how cells respond and behave in the presence of chemical gradients. The first approach (signal based approach) consists in exposing the cell to a gradient of chemoattractant and subsequently identifying and analyzing the signaling pathways and molecules involved in the migration process and that are in control of the oriented movement of the cell (Franca-Koh et al. 2006; Insall 2010; King and Insall 2009; Merlot and Firtel 2003; Schneider and Haugh 2006). The second and more recent approach (pseudopod based approach) focuses on how 
cells form and extend the pseudopodia and the acquired information are afterward related to what is already known about the established signaling patterns (Andrew and Insall 2007; Arrieumerlou and Meyer 2005; Bosgraaf and Van Haastert 2009a; Insall 2010; Li et al. 2008; Takagi et al. 2008).

From a numerical point of view, several studies have been proposed in the literature in order to decipher the mechanism by which the cell membrane protrude and extend. Two main approaches have been used to model cell migration: micro/nanostructural and continuum approaches (Lim et al. 2006). While the former considers the cytoskeleton as the principle actor of cell motility and try to investigate the mechanical processes which regulate it, the latter mostly focuses on a macroscale description of the cellular structure to take into account the large deformations of the membrane and understand how stresses and strains are distributed (Bottino et al. 2002; Mogilner and Verzi 2003; Rubinstein et al. 2005).

There exist at least four main hypotheses that have been largely explored in the last decades: (i) calcium concentration regulates the expansion and the contraction of the actin network through a sol/gel transition (Oster 1984), (ii) actin polymerization triggered by random thermal fluctuations in the cell membrane or in the actin filaments is the main promoter of protrusion (Carlier and Pantaloni 1997; Mogilner and Oster 1996; Theriot and Mitchison 1991), (iii) the extension of the cellular membrane is regulated by specific mechanisms at the molecular scale (Alt and Tranquillo 1995; Lee et al. 1993; Mogilner and Rubinstein 2005; Small et al. 1993; Stéphanou et al. 2004; Veksler and Gov 2007), and (iv) hydrostatic pressure generated by cytoplasmic flows inside the cell induces the protrusion of the membrane (Alt and Tranquillo 1995; Bereiter-Hahn and Lüers 1998; Oster and Perelson 1987; Taber et al. 2011; Young and Mitran 2010; Zhu and Skalak 1988). Finally, there are also those models with a significant mechanical component (see review in Carlsson and Sept (2008), Flaherty et al. (2007)), even though most of them are 1D or 2D and only few use a 3D finite element formulation (Rubinstein et al. 2005; Sakamoto et al. 2011; Stolarska et al. 2009; Taber et al. 2011).

The general conclusion is that the protrusion-contraction deformations of the cell are strongly connected to the polymerization-depolymerization processes of the actin network inside the cytoskeleton (Borisy and Svitkina 2000; Carlier and Pantaloni 1997; Condeelis 1993). Additionally, in the last decades, it has been experimentally demonstrated that the existence of the recurring pattern of deformation could be related to a self-organization of spontaneous deformation dynamics inside the cell (Alt 1990; Alt and Tranquillo 1995; Killich et al. 1993; Stéphanou et al. 2004) rather than to significant stimuli from the environment. Although so far very poorly explored, this is a fundamental aspect to consider, which may affect the response of the cell to external signals.

In this paper, a finite element model of a 3D cell migrating over a $2 \mathrm{D}$ substrate using pseudopodia is proposed, which is based on the following hypotheses:

- as in previous works (Borisy and Svitkina 2000; Carlier and Pantaloni 1997; Condeelis 1993; Mogilner and Oster 1996; Theriot and Mitchison 1991), the oscillating protrusion-contraction movement of the cell is assumed to be controlled by the cyclic polymerization/depolymerization of the actin network, which may occur at any site along the cell membrane where the actin filaments are concentrated; 
- a purely mechanical approach is used to describe the cell behavior as it has been proposed in previous models (Carlsson and Sept 2008; Flaherty et al. 2007; Rubinstein et al. 2005; Sakamoto et al. 2011; Taber et al. 2011). Nevertheless, a different mathematical method is applied. In fact, the decomposition of the deformation gradient is employed to take into account the active elementary strains undergone by the cell (i.e., protrusion and contraction) as well as the elastic deformations generated by the interaction of the cell with the underneath substrate;

- as in Stéphanou et al. (2004), large deformations of the cell membrane are considered which trigger the formation of multiple pseudopodia in response to external attractive sources. Additionally, in the present model, the cell may adopt two different strategies: whether it initiates several simultaneous pseudopodia and then it chooses the one which is the best oriented toward the chemoattractant (temporal sensing model) or it only protrudes one pseudopod in the direction of the external signal (spatial sensing model);

- finally, the protrusion of the pseudopodia and the contraction of the cell body are tightly synchronized with the adhesion forces at the back and at the front, respectively, which actually allow the forward movement of the cell over the substrate.

As similarly as in Allena and Aubry (2012), the main objective is to show that although the chemical, molecular, or genetic functions may play an important role during the biological phenomenon, the cell is strongly governed by fundamental mechanical principles that need to be taken into account (Murray 2003). Furthermore, the model is much more realistic with respect to the previous one (Allena and Aubry 2012) and the adaptability of the numerical formulation allows to reproduce the behavior of different types of cells, which could be a powerful feature for further applications.

\section{Modeling of Multiple Pseudopodia}

In this section, the main characteristics of the model are described. First, the cell and the pseudopodia geometry together with the constitutive model and the general mechanical framework are described. Second, a pseudopod centered approach in a steady active configuration is used to show the ability of the cell to initiate more than one false foot. Different forms of protrusion are then proposed, which allow obtaining morphologies that are typical of various animal cells.

\subsection{Cell and Pseudopodia Geometry}

As in Allena and Aubry (2012), the global geometry of the cell is obtained by superposing a cylinder and a spherical cap (Fig. 1a). As mentioned in Sect. 1.2, the protrusion and the contraction of the cell are regulated by the polymerization and depolymerization of the actin filaments, respectively, which are mostly located toward the outmost region of the cell (Schaub et al. 2007) and radially organized (Cramer et al. 1997). Accordingly, the actin network is here represented by an annulus of inner radius $r_{\text {annulus }}$ equal to $3 \mu \mathrm{m}$ (Fig. 1b), which is analytically given by

$$
\Omega_{\text {annulus }}(\boldsymbol{p})=h \circ l_{\text {annulus }}(\boldsymbol{p})
$$




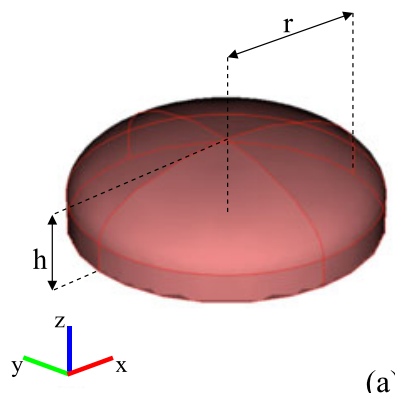

(a)

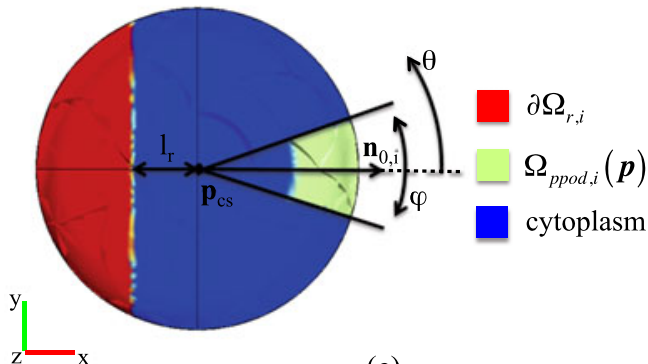

(c)

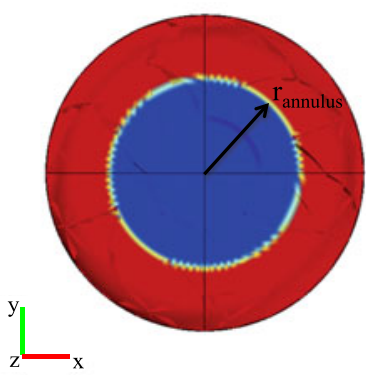

(b) actin network

cytoplasm

Fig. 1 (a) Geometry of the cell. (b) Top view of the cell at $z=0$. In red the actin network, which is defined by an annulus of inner radius $r_{\text {annulus }}$, and in blue the cytoplasm. (c) Top view of the cell at $z=0$. In green the pseudopod domain $\Omega_{\text {ppod, } i}(\boldsymbol{p})$, in red the rear adhesion surface $\partial \Omega_{r, i}$ and in blue the cytoplasm. (d) Sketch of the generalized Maxwell model used to the described the mechanical behavior of the system (Color figure online)

where $h$ is the classical Heaviside function (Eq. (29)) and $l_{\text {annulus }}(\boldsymbol{p})$ is the level set function of the annulus (Eq. (32)), with $\boldsymbol{p}$ the initial position of any particle of the cell.

Then a pseudopod can be initiated in any direction and its position is at the intersection between the annulus and cone of action defined in the $x, y$ plane as

$$
\Omega_{\text {cone }}(\boldsymbol{p})=h \circ l_{\text {cone }, i}(\boldsymbol{p})
$$

where $l_{\text {cone, } i}(\boldsymbol{p})$ is the level set function of the cone (Eq. (33)) and $i \in\{1,2, \ldots, N\}$ while $N$ is the number of pseudopodia. The cone has an apex angle $\varphi$ fixed here to $\frac{\pi}{10}$ (Fig. 1c).

Therefore, the pseudopod active domain $\Omega_{\text {ppod,i }}(\boldsymbol{p})$ can be expressed as

$$
\Omega_{\mathrm{ppod}, i}(\boldsymbol{p})=\Omega_{\text {cone }, i}(\boldsymbol{p}) \cdot \Omega_{\text {annulus }}(\boldsymbol{p})
$$

and it has an initial volume and length along the pseudopod axis $\boldsymbol{n}_{0, i}$ (Eq. (35), Fig. 1c) of about $10 \mu \mathrm{m}^{3}$ and $2 \mu \mathrm{m}$, respectively. For the present model, only de novo pseudopodia are considered. 


\subsection{Constitutive Model}

As described in Allena and Aubry (2012), all the body forces are neglected, but the inertial effects, which may play an important role, especially during protrusion (Gracheva and Othmer 2004). Thus, the global equilibrium of the system reads

$$
\rho \boldsymbol{a}=\operatorname{Div}_{p}\left(J \boldsymbol{\sigma} \mathbf{F}^{-T}\right)
$$

where $\rho$ is the cell density, $\boldsymbol{a}$ is the acceleration, $\boldsymbol{D i \boldsymbol { v }} \boldsymbol{p}$ is the divergence with respect to the initial position $\boldsymbol{p}, J$ is the determinant of the deformation gradient $\mathbf{F}$ and $\boldsymbol{A}^{-T}$ denotes the inverse transpose of the matrix $\boldsymbol{A}$ (Holzapfel 2000; Taber 2004). A generalized Maxwell model (Larson 1998) (Fig. 1d) is used to describe the Cauchy stress $\sigma$ and the deformation gradient $\mathbf{F}$ as follows:

$$
\begin{aligned}
& \boldsymbol{\sigma}=\boldsymbol{\sigma}_{s}+\boldsymbol{\sigma}_{f} \\
& \boldsymbol{F}=\boldsymbol{D}_{\boldsymbol{p}} \boldsymbol{u}+\boldsymbol{I}=\boldsymbol{F}_{s}=\boldsymbol{F}_{f}
\end{aligned}
$$

where $\boldsymbol{D}_{p} \boldsymbol{u}=\sum_{m=1}^{3} \frac{\partial \boldsymbol{u}}{\partial p_{m}} \otimes \boldsymbol{i}_{m}$, with $\boldsymbol{u}$ the displacement and $\boldsymbol{I}$ the identity matrix, respectively (Holzapfel 2000; Taber 2004). The indices $s$ and $f$ indicate the solid (actin filaments) and the fluid viscoelastic (cytoplasm with embedded organelles) phase, respectively.

As in previous works (Allena et al. 2010; Balan and Tsakmakis 2002; Bonet 2001; Lubarda 2004; Muñoz et al. 2007), the decomposition of the deformation gradient is employed to define both $\mathbf{F}_{s}$ and $\mathbf{F}_{f}$ as follows:

$$
\begin{aligned}
& \mathbf{F}_{s}=\mathbf{F}_{s e} \mathbf{F}_{s a} \\
& \mathbf{F}_{f}=\mathbf{F}_{f e} \mathbf{F}_{f v}
\end{aligned}
$$

In the solid phase, $\mathbf{F}_{s a}$ regulates the active protrusion-contraction movement of the cell and $\mathbf{F}_{s e}$ controls the stress generation inside the mechanical system. In the fluid phase, $\mathbf{F}_{f e}$ and $\mathbf{F}_{f v}$ represent the fluid elastic and the viscoelastic deformation, respectively.

The solid stress $\sigma_{s}$ is computed as an isotropic hyperelastic Saint-Venant material and it reads

$$
\sigma_{s}=\frac{1}{J_{s e}} \boldsymbol{F}_{s e} \boldsymbol{S}_{s e} \boldsymbol{F}_{s e}^{T}
$$

where $J_{s e}$ is the determinant of $\boldsymbol{F}_{s e}$ and $\boldsymbol{S}_{s e}$ is the second Piola-Kirchoff stress tensor of the solid elastic phase, which is defined as

$$
\boldsymbol{S}_{s e}=\lambda_{s} \operatorname{Tr}\left(\boldsymbol{E}_{s e}\right) \boldsymbol{I}+2 \mu_{s} \boldsymbol{E}_{s e}
$$

with $\lambda_{s}, \mu_{s}$, and $\boldsymbol{E}_{s e}$ are the Lame's coefficients and the Green-Lagrange strain tensor of the solid elastic phase, respectively.

In the fluid phase, the Cauchy stresses are assumed to be equal so that $\sigma_{f}=\sigma_{f e}=$ $\sigma_{f v}$. The fluid elastic Cauchy stress $\sigma_{f e}$ is given by an isotropic hyperelastic SaintVenant model as follows:

$$
\boldsymbol{\sigma}_{f e}=\frac{1}{J_{f e}} \boldsymbol{F}_{f e} \boldsymbol{S}_{f e} \boldsymbol{F}_{f e}^{T}
$$


with $J_{f e}$ the determinant of $\boldsymbol{F}_{f e}$ and $\boldsymbol{S}_{f e}$ is the second Piola-Kirchhoff stress tensor of the fluid elastic phase and it is given by

$$
\boldsymbol{S}_{f e}=\lambda_{f e} \operatorname{Tr}\left(\boldsymbol{E}_{f e}\right) \boldsymbol{I}+2 \mu_{f e} \boldsymbol{E}_{f e}
$$

where $\lambda_{f e}$ and $\mu_{f e}$ and $\boldsymbol{E}_{f e}$ are the Lame's coefficients and the Green-Lagrange strain tensor of the fluid elastic phase, respectively. by

Additionally, the deviator of the second Piola-Kirchhoff stress tensor $\boldsymbol{S}_{f e}^{D}$ is given

$$
\boldsymbol{S}_{f e}^{D}=2 \mu_{f v} \boldsymbol{D}_{f v}
$$

with $\mu_{f v}$ the viscosity of the fluid viscous phase and the Eulerian strain rate $\boldsymbol{D}_{f v}$ expressed as

$$
2 \boldsymbol{D}_{f v}=\dot{\boldsymbol{F}}_{f v} \boldsymbol{F}_{f v}^{-1}+\boldsymbol{F}_{f v}^{-T} \dot{\boldsymbol{F}}_{f v}^{T}
$$

The preceding equation allows determining the evolution law of $\boldsymbol{F}_{f v}$, which is numerically integrated.

\subsection{Steady Active Protrusion}

The active part of the solid deformation gradient $\mathbf{F}_{s}$ usually defines the protrusion and the contraction of the cell (Allena and Aubry 2012). In this first part of the work, instead only the protrusion phase is taken into account to describe a steady active configuration during which the cell is able to form and extend multiple pseudopodia. As in Allena and Aubry (2012), $\mathbf{F}_{s a}$ is modeled as a uniaxial deformation as

$$
\mathbf{F}_{s a}=\sum_{i=1}^{N}\left(e_{a p, i}(t) \boldsymbol{n}_{i} \otimes \boldsymbol{n}_{i}\right)
$$

where $\boldsymbol{n}_{i}$ is the normal vector in the actual configuration expressed as Holzapfel (2000)

$$
\boldsymbol{n}_{i}=\frac{\mathbf{F}^{-T} \cdot \boldsymbol{n}_{0, i}}{\left\|\mathbf{F}^{-T} \cdot \boldsymbol{n}_{0, i}\right\|}
$$

with $\|\cdot\|$ defining the norm of a vector.

The cyclic component of the protrusion $e_{a p, i}$ can assume here three different forms as follows:

(1) the active deformation is applied everywhere through a gradient along the axis of the pseudopod $\boldsymbol{n}_{0, i}$ as follows:

$$
e_{a p, i}(t)=e_{a p 0} \mathrm{~T}_{p}(t)\left(1+\alpha p_{d, i}\right)
$$

where $t$ is the time, $e_{a p 0}$ is the amplitude of the cyclic active strain, which can be either constant or random, $p_{d, i}$ is defined in Eq. (34) and $\alpha$ is a constant that determines the amplitude of the gradient and it is equal here to 0.8 . The duration of the protrusion phase is given by $\mathrm{T}_{p}(t)=h \circ l_{p}(t)$, where $l_{p}(t)$ is the level set function defined in Eq. (36), and is equal to half the duration of a migration cycle $T_{\mathrm{migr}}$, which has been fixed here to $60 \mathrm{~s}$ (Allena and Aubry 2012; Dong et al. 2002); 
(2) the protrusion is applied only in the pseudopod active domain $\Omega_{\text {ppod, } i}(\boldsymbol{p})$, thus the uniform elongation is expressed as

$$
e_{a p, i}(t)=e_{a p 0} \mathrm{~T}_{p}(t) \Omega_{\mathrm{ppod}, i}(\boldsymbol{p})
$$

(3) finally a combination of the two previous modes of deformation modes is considered

$$
e_{a p, i}(t)=e_{a p 0} \mathrm{~T}_{p}(t)\left(1+\alpha p_{d, i}\right) \Omega_{\mathrm{ppod}, i}(\boldsymbol{p})
$$

As it will be shown later on, each one of these patterns of the active deformation will lead to different final shapes of the cell. This is an interesting aspect of the present work, which simultaneously points out the flexibility of the mechanical formulation and the ability of the model to describe the behavior of various kinds of cell.

\section{Migration}

In this section, a signal centered approach is employed to describe the migration process of the cell over a 2D substrate. One or more external sources are introduced in the system in response to which the cell initiates one or multiple pseudopodia according to the strategy employed to move forward: the spatial or the temporal sensing model, respectively.

\subsection{Temporal Sensing Model}

In the temporal sensing model, the cell first explores the environment by simultaneously protruding several pseudopodia. Then the cell adheres to the substrate using only one pseudopod, the best oriented toward the external source, retract the other pseudopodia, and contract the entire body in the direction of the selected pseudopod. Therefore, the solid active deformation gradient $\mathbf{F}_{s a}$ can be expressed as

$$
\mathbf{F}_{s a}=\sum_{i=1}^{N}\left[\Theta_{\operatorname{crit} 1, i}\left(\theta_{i}\right) e_{a p, i}(t)+\Theta_{\mathrm{crit} 1, i}\left(\theta_{i}\right) \Theta_{\mathrm{crit}, i}\left(\theta_{i}\right) \Theta_{\mathrm{crit} 3, i}\left(\theta_{i}\right) e_{a c, i}(t)\right] \boldsymbol{n}_{i} \otimes \boldsymbol{n}_{i}
$$

with $\theta_{i}$ the angle of the pseudopod $\Omega_{\mathrm{ppod}, i}$ and $e_{a c, i}$ the cyclic deformation for the uniform contraction of the body cell which is defined as

$$
e_{a c, i}(t)=e_{a c 0} \mathrm{~T}_{c}(t)
$$

where $\mathrm{T}_{c}(t)=h \circ l_{c}(t)$ and $l_{c}(t)$ is the level set function defined in Eq. (36).

During the protrusion phase, the cell may extend multiple pseudopodia, but as experimentally observed (Bosgraaf and Van Haastert 2009a), there has to be a minimal distance between them equal to $\frac{\pi}{36}$. The function $\Theta_{\text {crit } 1, i}\left(\theta_{i}\right)=h \circ l_{\text {crit } 1, i}\left(\theta_{i}\right)$, where $l_{\text {crit } 1, i}\left(\theta_{i}\right)$ is defined in Eq. (37), takes into account such a condition for each pseudopod.

For the contraction to occur, three conditions have to be satisfied:

(1) $\Theta_{\text {crit } 1, i}\left(\theta_{i}\right)$ has to be equal to one for at least one pseudopod; 
(2) if $\Theta_{\text {crit } 1, i}\left(\theta_{i}\right)=1$ for more than one pseudopod, then the cell has to evaluate which one among the extended pseudopodia is the best oriented toward the external source, which is defined by its direction $\theta_{\text {source }, i}$. Such a criterion has been implemented in the model through the function $\Theta_{\text {crit } 2, i}\left(\theta_{i}\right)=h \circ l_{\text {crit } 2, i}\left(\theta_{i}\right)$, with $l_{\text {crit } 2, i}\left(\theta_{i}\right)$ defined in Eq. (38).

(3) finally, the direction $\theta_{i}$ of the pseudopod $i$ satisfying conditions (1) and (2) has to be in the same quadrant of $\theta_{\text {source }, i}$. The function $\Theta_{\text {crit3,i }}\left(\theta_{i}\right)=h \circ l_{\text {crit } 3, i}\left(\theta_{i}\right)$, with $l_{\text {crit3,i }}\left(\theta_{i}\right)$ expressed as in Eq. (39), allows taking into account such an aspect.

If no one of the previous criteria is satisfied for any pseudopod, then the cell will not contract and, therefore, not move forward.

\subsection{Spatial Sensing Model}

In the spatial sensing model, the cell senses the surroundings at different points of the membrane, but it only protrudes one pseudopod at the time in the direction of the most attractive source.

Let $\tau_{\text {source, } i}(t)$ and $\theta_{\text {source, } i}$ being the intensity and the direction of each source respectively. Then, $\theta_{i}=\theta_{\text {source }, i \max }$ with

$$
i \max =\operatorname{Arg}\left\{\max _{i}\left(\tau_{\text {source }, i}\right)\right\}
$$

where $i=1, \ldots, N_{\text {source }}$, with $N_{\text {source }}$ the total number of external sources.

Thus, the solid active deformation gradient $\mathbf{F}_{s a}$ reads now

$$
\mathbf{F}_{s a}=\left[e_{a p, i}(t)+e_{a c, i}(t)\right] \boldsymbol{n}_{i \max } \otimes \boldsymbol{n}_{i \max }
$$

\subsection{Adhesion Forces}

In order for the cell to move forward, some forces are necessary to adhere to the underneath 2D substrate at the leading and at the rear edge of the cell alternatively. The frontal adhesion surface $\partial \Omega_{f, i}$ always coincides with the contact surface between the substrate and the pseudopod selected for the migration in the direction $\boldsymbol{n}_{i}$ (area of $5.5 \mu \mathrm{m}^{2}$, Fig. 1c) and is then defined by

$$
\partial \Omega_{f, i}\left(\boldsymbol{p}_{s}\right)=\partial \Omega_{\mathrm{ppod}, i}\left(\boldsymbol{p}_{s}\right)=\partial \Omega_{\mathrm{cone}, i}\left(\boldsymbol{p}_{s}\right) \cdot \partial \Omega_{\text {annulus }}\left(\boldsymbol{p}_{s}\right)
$$

where

$$
\begin{aligned}
& \partial \Omega_{\text {annulus }}\left(\boldsymbol{p}_{s}\right)=h \circ l_{\text {annulus }}\left(\boldsymbol{p}_{s}\right) \\
& \partial \Omega_{\text {cone }, i}\left(\boldsymbol{p}_{s}\right)=h \circ l_{\text {cone }, i}\left(\boldsymbol{p}_{s}\right)
\end{aligned}
$$

with $l_{\text {annulus }}\left(\boldsymbol{p}_{s}\right)$ and $l_{\text {cone }, i}\left(\boldsymbol{p}_{s}\right)$ defined in Eq. (40).

Similarly, for each pseudopod, there exists a rear adhesion surface $\partial \Omega_{r, i}$ (area of $25 \mu^{2}$, Fig. 1c), which reads

$$
\partial \Omega_{r, i}\left(\boldsymbol{p}_{S}\right)=h \circ l_{r, i}\left(\boldsymbol{p}_{S}\right)
$$

with $l_{r, i}\left(\boldsymbol{p}_{s}\right)$ defined in Eq. (41).

As in Allena and Aubry (2012) and in previous works (Friedl and Gilmour 2009; Phillipson et al. 2006), the adhesion forces are assumed to be viscous forces and they read differently according to the strategy adopted by the cell to migrate. 
In the temporal sensing model, they are expressed as follows:

$$
\begin{aligned}
& \sigma_{f, \text { temp }}\left(\mathbf{n}_{0, i}\right)=-\mu_{f f} \mathbf{T}_{a f}(t) \frac{\partial \boldsymbol{u}_{s}}{\partial t} \sum_{i=1}^{N}\left[\partial \Omega_{f, i}\left(\boldsymbol{u}_{s}\right) \Theta_{\text {crit } 1, i}\left(\theta_{i}\right) \Theta_{\text {crit } 2, i}\left(\theta_{i}\right) \Theta_{\text {crit } 3, i}\left(\theta_{i}\right)\right] \\
& \text { on } \partial \Omega_{f, i} \\
& \sigma_{r, \text { temp }}\left(\mathbf{n}_{0, i}\right)=-\mu_{f r} \mathrm{~T}_{a r}(t) \frac{\partial \boldsymbol{u}_{s}}{\partial t} \sum_{i=1}^{N}\left[\partial \Omega_{r, i}\left(\boldsymbol{u}_{s}\right) \Theta_{\text {crit } 1, i}\left(\theta_{i}\right) \Theta_{\text {crit } 2, i}\left(\theta_{i}\right) \Theta_{\text {crit } 3, i}\left(\theta_{i}\right)\right] \\
& \quad \text { on } \partial \Omega_{r, i}
\end{aligned}
$$

with $\mu_{f f}$ and $\mu_{f r}$ the friction coefficients for the frontal and rear surfaces equal to $10^{8} \mathrm{~Pa} \mathrm{~s}$, respectively, and $\boldsymbol{u}_{s}$ the tangential displacement of the cell with respect to the substrate. In this case, the viscous forces are only activated in the pseudopodia for which the three conditions $\Theta_{\text {crit } 1, i}\left(\theta_{i}\right), \Theta_{\text {crit } 2, i}\left(\theta_{i}\right)$, and $\Theta_{\text {crit } 3, i}\left(\theta_{i}\right)$ are simultaneously equal to one.

In the spatial sensing model instead, only one pseudopod is formed at each migration cycle, thus the viscous forces are activated in this selected false foot and in the associated rear region as follows:

$$
\begin{aligned}
& \sigma_{f, \text { spat }}\left(\mathbf{n}_{0, i \max }\right)=-\mu_{f f} \mathrm{~T}_{a f}(t) \frac{\partial \boldsymbol{u}_{s}}{\partial t} \partial \Omega_{f, i \max }\left(\boldsymbol{u}_{s}\right) \quad \text { on } \partial \Omega_{f, i \max } \\
& \sigma_{r, \text { spat }}\left(\mathbf{n}_{0, i \max }\right)=-\mu_{f r} \mathrm{~T}_{a r}(t) \frac{\partial \boldsymbol{u}_{s}}{\partial t} \partial \Omega_{r, i \max }\left(\boldsymbol{u}_{s}\right) \quad \text { on } \partial \Omega_{r, i \max }
\end{aligned}
$$

As amply discussed and demonstrated in Allena and Aubry (2012), such forces play a fundamental role during the migration process. In fact, the cell would only deform on place if no adhesion force were activated. Therefore, $\sigma_{f, \text { temp }}\left(\mathbf{n}_{0, i}\right), \sigma_{f \text {,spat }}\left(\mathbf{n}_{0, i \text { max }}\right)$, and $\sigma_{r \text {,temp }}\left(\mathbf{n}_{0, i}\right), \sigma_{r \text {,spat }}\left(\mathbf{n}_{0, i \max }\right)$ are perfectly synchronized with the contraction and the protrusion phases through the functions $\mathrm{T}_{a f}(t)=h \circ l_{a f}(t)$ and $\mathrm{T}_{a r}(t)=$ $h \circ l_{a r}(t)$, respectively, with $l_{a f}(t)$ and $l_{a r}(t)$ defined in Eq. (42). Additionally, a small viscous force is applied over the whole contact surface between the cell and the substrate as the cell constantly lies on the substrate.

\section{Results}

The numerical simulations have been run using the finite element software COMSOL Multiphysics $^{\circledR} 3.5 \mathrm{a}$. The cell has an initial geometry with a radius $r$ of $5 \mu \mathrm{m}$ and a maximal height $h$ along the axis of symmetry of $3 \mu \mathrm{m}$. The Young's modulus $E_{s}$ and the Poisson's ratio $v_{s}$ for the solid phase of the model have been chosen uniformly equal to $10^{4} \mathrm{~Pa}$ (Laurent et al. 2005) and 0.3, respectively. For the fluid phase, $E_{f e}$ and $v_{f e}$ are equal to $10^{2} \mathrm{~Pa}$ and 0.4 , respectively, while the viscosity $\mu_{f v}$ is equal to $3 \times 10^{5} \mathrm{~Pa} \mathrm{~s}$ (Bausch et al. 1999; Drury and Dembo 2001). The cell density $\rho$ has been set to $1000 \mathrm{~kg} / \mathrm{m}^{3}$ (Fukui et al. 2000). The main geometrical, material, and mechanical parameters are listed in Table 1. 
Table 1 Main geometrical, material, and mechanical parameters

\begin{tabular}{|c|c|c|c|c|}
\hline Parameter & Description & Value & Unit & Reference \\
\hline$r$ & Cell radius & $5 \times 10^{-6}$ & $\mathrm{~m}$ & \\
\hline$h$ & Cell height & $3 \times 10^{-6}$ & $\mathrm{~m}$ & \\
\hline$r_{\text {annulus }}$ & Annulus radius & $3 \times 10^{-6}$ & $\mathrm{~m}$ & \\
\hline$\varphi$ & Cone apex angle & $\frac{\pi}{10}$ & $\operatorname{rad}$ & \\
\hline$E_{S}$ & $\begin{array}{l}\text { Young's modulus for the } \\
\text { solid phase }\end{array}$ & $10^{4}$ & $\mathrm{~Pa}$ & Laurent et al. (2005) \\
\hline$v_{s}$ & $\begin{array}{l}\text { Poisson's ratio for the } \\
\text { solid phase }\end{array}$ & 0.3 & & \\
\hline$E_{f e}$ & $\begin{array}{l}\text { Young's modulus for the } \\
\text { fluid-elastic phase }\end{array}$ & $10^{2}$ & $\mathrm{~Pa}$ & \\
\hline$v_{f e}$ & $\begin{array}{l}\text { Poisson's ratio for the } \\
\text { fluid-elastic phase }\end{array}$ & 0.4 & & \\
\hline$\mu_{f v}$ & $\begin{array}{l}\text { Viscosity for the } \\
\text { fluid-viscous phase }\end{array}$ & $3 \times 10^{5}$ & Pas & $\begin{array}{l}\text { Bausch et al. (1999), } \\
\text { Drury and Dembo } \\
(2001)\end{array}$ \\
\hline$\rho$ & Cell density & 1000 & $\mathrm{~kg} / \mathrm{m}^{3}$ & Fukui et al. (2000) \\
\hline$e_{a p 0}$ & Cyclic active protrusion & 0.5 & & \\
\hline$e_{a c 0}$ & Cyclic active contraction & 0.2 & & \\
\hline$\alpha$ & Gradient amplitude & 0.8 & & \\
\hline$\partial \Omega_{f, i}$ & $\begin{array}{l}\text { Area of frontal region of } \\
\text { adhesion }\end{array}$ & $5.5 \times 10^{-6}$ & $\mathrm{~m}^{2}$ & \\
\hline$\partial \Omega_{r, i}$ & $\begin{array}{l}\text { Area of rear region of } \\
\text { adhesion }\end{array}$ & $25 \times 10^{-6}$ & $\mathrm{~m}^{2}$ & \\
\hline$\mu_{f f}$ & $\begin{array}{l}\text { Friction coefficient at the } \\
\text { frontal edge }\end{array}$ & $10^{8}$ & $\mathrm{~Pa} \mathrm{~s} / \mathrm{m}$ & \\
\hline$\mu_{f r}$ & $\begin{array}{l}\text { Friction coefficient at the } \\
\text { rear edge }\end{array}$ & $10^{8}$ & $\mathrm{~Pa} \mathrm{~s} / \mathrm{m}$ & \\
\hline \multirow[t]{2}{*}{$T_{\text {migr }}$} & Period for migration cycle & 60 & $\mathrm{~s}$ & $\begin{array}{l}\text { Allena and Aubry } \\
(2012) \text {, Dong et al. } \\
(2002)\end{array}$ \\
\hline & $\begin{array}{l}\text { Minimal distance between } \\
\text { pseudopodia }\end{array}$ & $\pm \frac{\pi}{36}$ & & $\begin{array}{l}\text { Bosgraaf and Van } \\
\text { Haastert (2009a) }\end{array}$ \\
\hline$\theta_{\sigma o v \rho \chi \varepsilon, \iota}$ & Source direction & $\begin{array}{l}\text { Temporal sensing } \\
\text { model: } \theta_{\text {source }, 1}=\frac{\pi}{4} \\
\text { Spatial sensing model: } \\
\theta_{\text {source }, 1}=0 \\
\theta_{\text {source }, 2}=\frac{2 \pi}{3} \\
\theta_{\text {source }, 3}=\frac{4 \pi}{3}\end{array}$ & & \\
\hline
\end{tabular}

\subsection{Multiple Pseudopodia}

The objective here is to show the ability of the cell to initiate and extend multiple pseudopodia, up to $N=8$, even though in reality configurations with more than four pseudopodia are rare because very unstable (Stéphanou et al. 2004). In this first series of simulations then, only the protrusion is implemented in the model and the cell does 
not migrate but only deforms on place. The cyclic component of the active strain $e_{a p 0}$ has been fixed equal to 0.5. As described in Sect. 2.3, several forms of protrusion have been tested.

In the very first row (a:e) of Fig. 2, five different initial configurations are presented at $t=0$ : (a) only one pseudopod $\left(\theta_{1}=0\right)$, (b) two pseudopodia $\left(\theta_{1}=0, \theta_{2}=\pi\right)$, (c) three pseudopodia $\left(\theta_{1}=0, \theta_{2}=\frac{2 \pi}{3}, \theta_{2}=\frac{4 \pi}{3}\right)$, (d) four pseudopodia $\left(\theta_{1}=0\right.$, $\left.\theta_{2}=\frac{\pi}{2}, \theta_{3}=\pi, \theta_{4}=\frac{3 \pi}{2}\right)$, and (e) eight pseudopodia $\left(\theta_{1}=0, \theta_{2}=\frac{\pi}{4}, \theta_{3}=\frac{\pi}{2}\right.$, $\theta_{4}=\frac{3 \pi}{4}, \theta_{5}=\pi, \theta_{6}=\frac{3 \pi}{2}, \theta_{7}=\frac{5 \pi}{4}, \theta_{7}=\frac{7 \pi}{4}$ ). The successive rows (f:j, k:o, p:t) of Fig. 2 represent the magnitude of the deformation at the end of the first protrusion phase $(30 \mathrm{~s})$ of the pseudopodia. In Fig. $2 \mathrm{f}: \mathrm{j}$, a gradient of the active deformation is implemented in the whole cell domain along the directions $\theta_{i}$ of the pseudopodia (Eq. (15)). In the case of two (f), four (i), and eight (j) pseudopodia, such a pattern of deformation does not produce realistic false feet, but rather a uniform ellipsoidal (f) or radial ( $\mathrm{i}$ and $\mathrm{j}$ ) deformation, and thus an extension of about $5 \mu \mathrm{m}$ (f), $5 \mu \mathrm{m}$ (i), and $10 \mu \mathrm{m}(\mathrm{j})$, respectively. In the case of one pseudopod (f), there is actually a protrusion of the frontal edge of the cell with a maximal elongation of $6 \mu \mathrm{m}$, while the rear end seems to contract of about $1 \mu \mathrm{m}$. Finally, in the case of three pseudopodia (h), the final protrusion leads to a star-shape configuration very similar to the one observed in fibroblasts (Fig. 3). This type of cell in fact usually exhibits between two or four long and narrow membrane extensions (filipodia) in opposite directions around the cell body (Stéphanou et al. 2004). The maximal elongation of the pseudopodia in this case is $7 \mu \mathrm{m}$. The third row (k:o) of Fig. 2 shows the morphology of the cell when a uniform active deformation is implemented only in the pseudopod domain (Eq. (16)). This pattern leads then to a maximal elongation of $1 \mu \mathrm{m}$ for each pseudopod in all the cases.

Finally, Fig. 2 p:t represents the deformation as described in Eq. (17) according to which a gradient of the active deformation along the direction $\boldsymbol{n}_{0, i}$ is implemented in the pseudopod domain. Although the smaller extension undergone by each pseudopod $(4 \mu \mathrm{m})$ and the more rounded shape (typical of the lobopodia in amoeboid cells), here the final morphologies (Fig. 2q, r, and s) are again very similar to the ones observed in Stéphanou et al. (2004) (Fig. 3). These preliminary results point out the ability of the model to reproduce different patterns of deformation and, therefore, the behavior of different types of cells. Since our previous study (Allena and Aubry 2012) was focused on amoeboid cells, the same will be done here and the third mode of deformation (gradient of the active strain along the direction $\boldsymbol{n}_{0, i}$, applied in the pseudopod domain) will be adopted in the other simulations.

\subsection{Randomness}

In reality, it is very unusual to observe regular and symmetric shapes as described in the previous section. Randomness, in fact, plays a significant role during the migration process. In this section, it will be shown how the magnitude of the cyclic active strain $e_{a p 0}$ and the direction $\theta_{i}$ of the pseudopodia can randomly vary throughout the time. For this purpose, the four pseudopodia cells (Fig. 2d) will be taken as an example. 


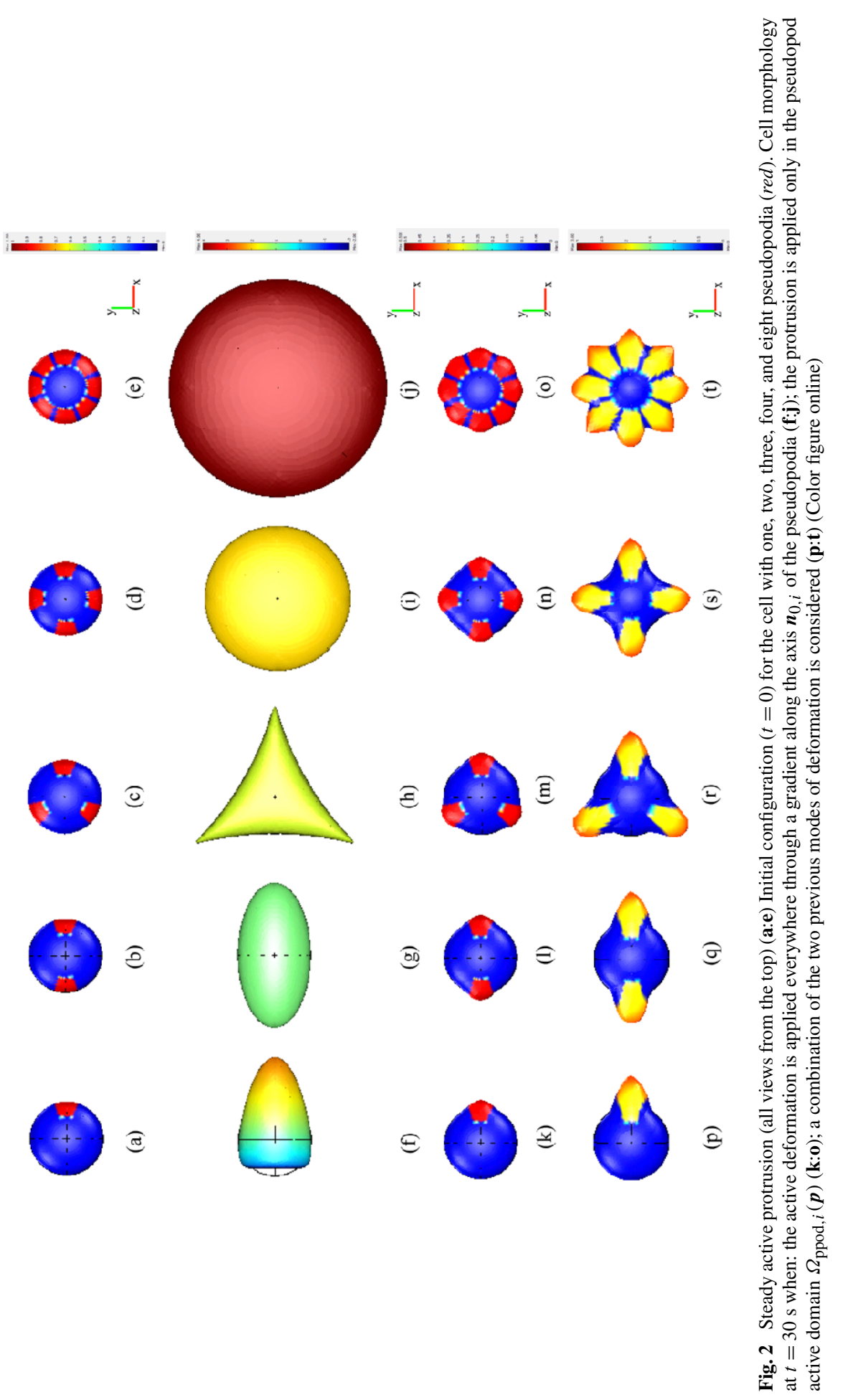


Fig. 3 Images originally appeared in Stéphanou et al. (2004), used by the permission of A. Stéphanou. (a) Typical morphologies of nonmigrating L929 fibroblasts observed with phase contrast microscopy.

(b) From the top to the bottom, videomicroscopy sequence of a L929 pulsating fibroblast

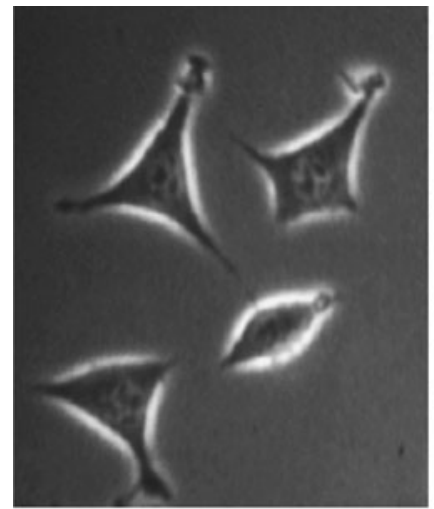

(a)

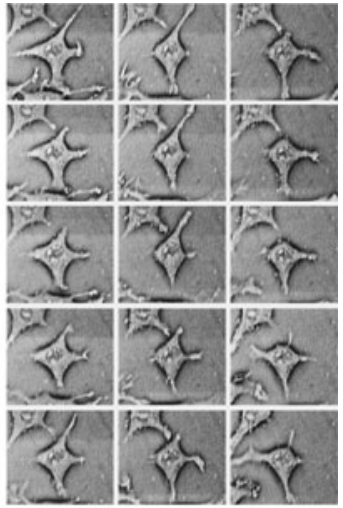

(b)

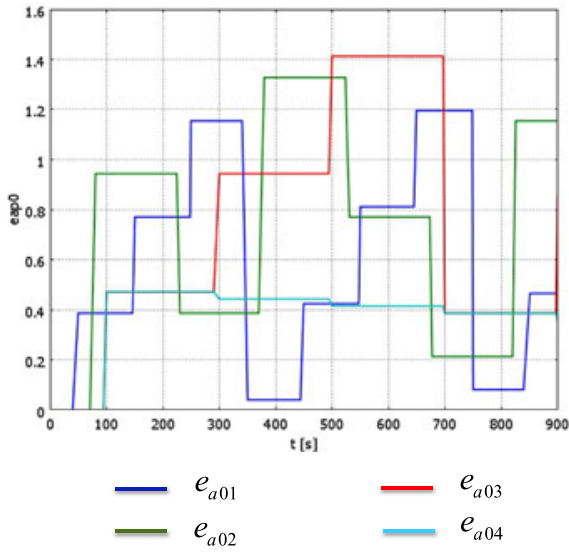

(a)

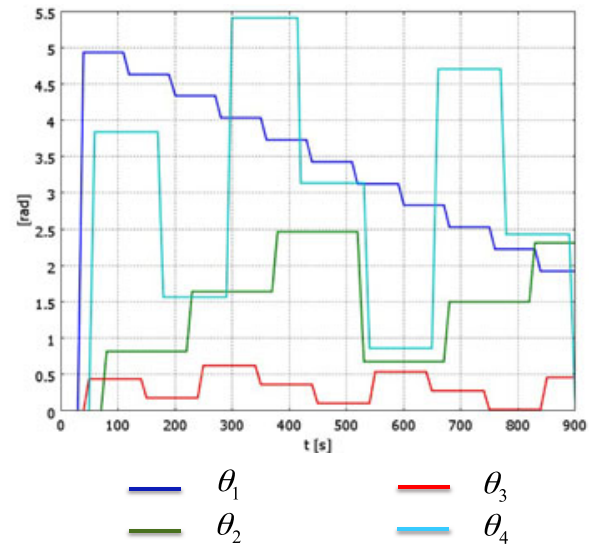

(b)

Fig. 4 Steady active protrusion for a cell with four pseudopodia. (a) and (b) Variation of the cyclic component $e_{a 0, i}$ and of the direction $\theta_{i}$ over time for each pseudopod, respectively (Color figure online)

First, the cyclic components $e_{a p 0}$ of the active deformation for each pseudopod randomly vary between 0 and 1.5 (Fig. 4a). Such a variation occurs over different periods, which have been set equal to $T_{e_{a 0}, 1}=100 \mathrm{~s}, T_{e_{a 0}, 2}=150 \mathrm{~s}, T_{e_{a 0}, 3}=200 \mathrm{~s}$, $T_{e_{a 0}, 1}=200 \mathrm{~s}$ for each pseudopod, respectively. Thus, the value of $e_{a p 0}$ changes for each false foot at different time steps, which adds a further random component. In Fig. 5, snapshots at different time steps are presented $(t=0,150,320,500,680$, $870 \mathrm{~s}$ ). The maximal and the minimal extensions observed are respectively of $9.5 \mu \mathrm{m}$ and $1 \mu \mathrm{m}$.

Second, the amplitude $e_{a p 0}$ of the active deformation is restored to 0.5 and the directions $\theta_{i}$ of each pseudopod randomly vary between 0 and $2 \pi$ over different periods for each pseudopod ( $T_{\theta, 1}=180 \mathrm{~s}, T_{\theta, 2}=150 \mathrm{~s}, T_{\theta, 3}=100 \mathrm{~s}, T_{\theta, 4}=120 \mathrm{~s}$, Fig. $\left.4 \mathrm{~b}\right)$. In Fig. 6, snapshots at time steps $t=0,150,320,500,680,870 \mathrm{~s}$ are presented. As the direction of each pseudopod randomly changes, it may happen that two or more 


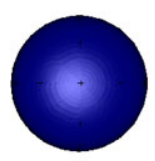

(a) $0 \mathrm{~s}$

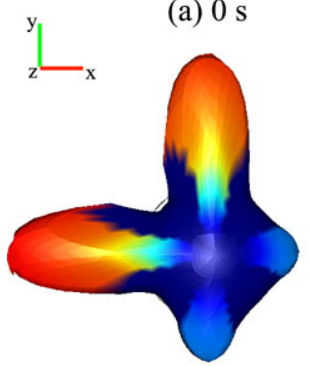

(d) $500 \mathrm{~s}$

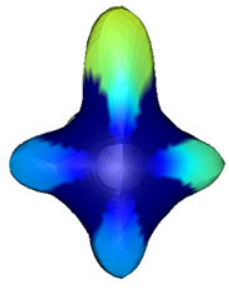

(b) $150 \mathrm{~s}$

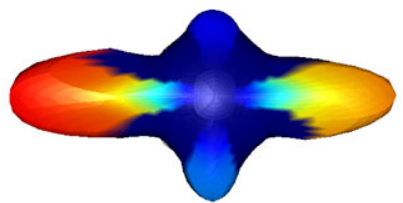

(e) $680 \mathrm{~s}$

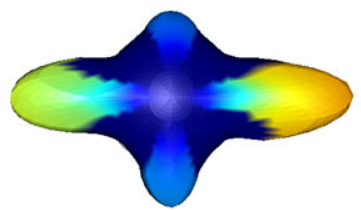

(c) $320 \mathrm{~s}$

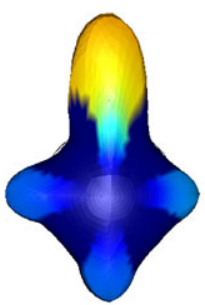

(f) $870 \mathrm{~s}$

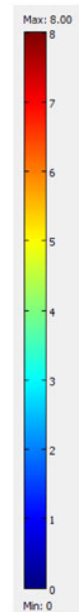

Fig. 5 Snapshots from the top at successive time steps for the steady active protrusion of a cell with four pseudopodia when the cyclic component $e_{a p 0}$ randomly varies over time for each false foot (colors: final deformation) (Color figure online)

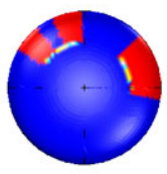

(a) $0 \mathrm{~s}$

${ }_{\mathrm{z}-\mathrm{x}}^{\mathrm{y}}$

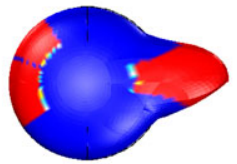

(d) $500 \mathrm{~s}$

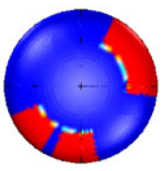

(b) $150 \mathrm{~s}$

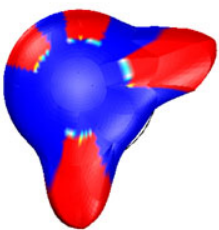

(e) $680 \mathrm{~s}$

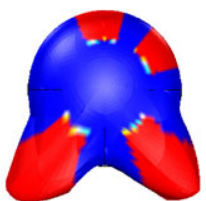

(c) $320 \mathrm{~s}$

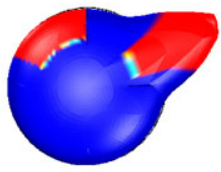

(f) $870 \mathrm{~s}$

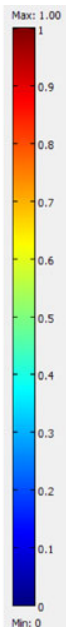

Fig. 6 Snapshots at successive time steps for the steady active protrusion of a cell with four pseudopodia when the direction $\theta_{i}$ randomly varies over time for each false foot (in red the pseudopodia) (Color figure online)

false feet totally or partially superpose. In this case, the pseudopodia cannot extend since, according to the literature (Bosgraaf and Van Haastert 2009b), the protrusion is only possible if the false foot is at a minimal distance of $\frac{\pi}{36}$ with respect to the very next pseudopodia. Therefore, when such a condition is not verified for two or 


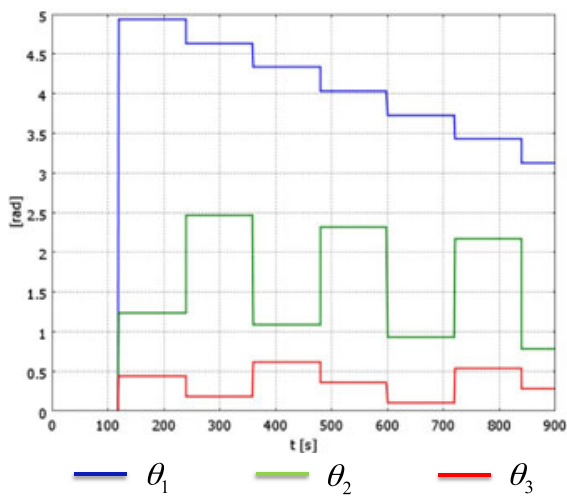

(a)

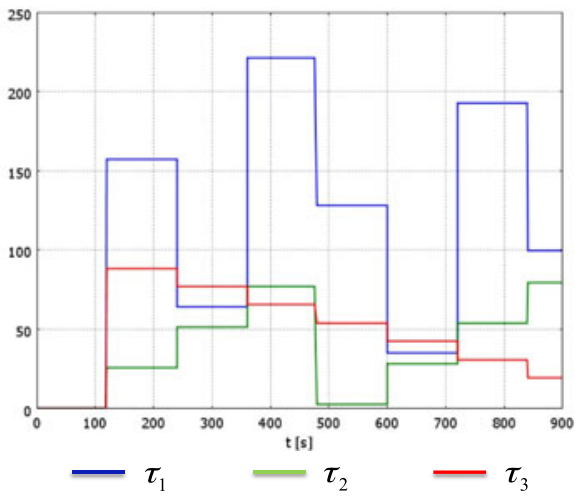

(b)

Fig. 7 (a) and (b) Variation of the direction $\theta_{i}$ and of the sources intensities $\tau_{\text {source, } i \text { over time for each }}$ pseudopod in the temporal and the spatial sensing model, respectively (Color figure online)

more pseudopodia $\left(h_{\mathrm{crit} 1, i}=0\right.$, see Sect. 3.1), these are not initiated as it is possible to observe in Fig. 6 at different time steps.

\subsection{Migration}

When the cell forms multiple pseudopodia, the migration can occur in two different ways: either the cell simultaneously extends several pseudopodia and then chooses the best oriented toward the external signal to move forward (temporal sensing model) or it only initiates one pseudopod in the direction of the most attractive source (spatial sensing model). In any case, only one pseudopod is employed by the cell to migrate. Here, the results obtained for the simulations of the two strategies are described. In both cases, a cell able to protrude up to three pseudopodia $(N=3)$ has been used as an example. The cyclic components of the active protrusion $e_{a p 0}$ and contraction $e_{a c 0}$ have been set equal to 0.5 and 0.2 , respectively. Such a difference in magnitude has been introduced in agreement with the literature according to which the deformation during the protrusion phase is larger than the one observed during the contraction phase (Gracheva and Othmer 2004).

\subsubsection{Temporal Sensing Model}

In the temporal sensing model, the directions $\theta_{1}, \theta_{2}$, and $\theta_{3}$ of the pseudopodia, perpendicular to the cell membrane, vary with respect to time (Fig. 7a) and the periods $T_{\theta, 1}, T_{\theta, 2}, T_{\theta, 3}$ are all equal to $120 \mathrm{~s}$, which corresponds to two migration cycles. An external source is introduced in the system and $\theta_{\text {source }, 1}=\frac{\pi}{4}$. As amply discussed and demonstrated in Allena and Aubry (2012), the cell needs to adhere to the underneath substrate in order to move forward. Thus, according to Eq. (26), during the protrusion phase the rear adhesion force is activated in the rear regions associated to the pseudopodia for which $\Theta_{\text {crit } 1, i}\left(\theta_{i}\right), \Theta_{\text {crit } 2, i}\left(\theta_{i}\right)$ and $\Theta_{\text {crit } 3, i}\left(\theta_{i}\right)$ are simultaneously satisfied. During the contraction phase, the same conditions have to be verified and the region of adhesion coincides with the contact surface between the substrate and 
the pseudopod selected for the migration. Movie 1 shows the successive steps of the migration over $900 \mathrm{~s}$. The cell is able to extend three pseudopodia in different directions if there is a minimal distance of $\frac{\pi}{36}$ between each other according to $\Theta_{\text {crit } 1, i}\left(\theta_{i}\right)$. If a superposition of two or more pseudopodia occurs, the cell does not protrude them. The contraction phase only takes place if $\Theta_{\text {crit } 1, i}\left(\theta_{i}\right), \Theta_{\text {crit } 2, i}\left(\theta_{i}\right)$, and $\Theta_{\text {crit } 3, i}\left(\theta_{i}\right)$ are simultaneously equal to one for at least one false foot, otherwise the cell does not move forward. In Figs. 8a and b, the trajectory over the substrate and the displacement of the cell center of mass are represented. As it can be observed (Fig. 8b), there is an initial phase $(0-120 \mathrm{~s})$ during which nothing happens because the three directions $\theta_{1}, \theta_{2}$, and $\theta_{3}$ are all equal to zero, thus $\Theta_{\text {crit } 1, i}\left(\theta_{i}\right)$ is not verified. Between 120-240 s, the cell only extends one pseudopod since the other two coincide, but it does not move forward because the direction $\theta_{1}$ of this false foot is not in the same quadrant of the external source $\theta_{\text {source, } 1}$, thus $\Theta_{\text {crit } 3, i}\left(\theta_{i}\right)$ is different than one. Therefore, no displacement is observed and the cell only deforms on place (steady active phase). A similar situation takes place between 360-480 s, 600-720 s, and 840-900 s (Fig. 8b). The cell starts moving at $t=240 \mathrm{~s}$ until $t=360 \mathrm{~s}$ in the direction $\theta_{3}$ of the pseudopod, which is the best oriented with respect to the attractant and for which then the three conditions $\Theta_{\text {crit } 1, i}\left(\theta_{i}\right), \Theta_{\text {crit } 2, i}\left(\theta_{i}\right), \Theta_{\text {crit } 3, i}\left(\theta_{i}\right)$ are simultaneously verified. Two other phases of migration take place between $480-600 \mathrm{~s}$ and 720-840 s. The overall displacement of the cell center of mass is of about $28 \mu \mathrm{m}$ (Fig. 8b). In Fig. 8c, the trend of the velocity of the cell center of mass can be observed. During the stead active phases, the cell center of mass actually moves due to the protrusion of the pseudopodia, but its velocity is very small $(\sim 0.2 \mu \mathrm{m} / \mathrm{min})$. During the migration phases, the velocity increases and it is bigger during the contraction $(\sim 8.1 \mu \mathrm{m} / \mathrm{min}$, green line Fig. 8c) than the protrusion $(\sim 4.2 \mu \mathrm{m} / \mathrm{min}$, blue line Fig. 8c) phase. Although such values are in agreement with the ones experimentally found (Adachi et al. 2009; Okeyo et al. 2009; Wilson et al. 2010), some remarks may be done. First, a smaller velocity during the protrusion phase is due to the fact that the extension mainly occurs locally at the pseudopod domain $\Omega_{\mathrm{ppod}, i}(\boldsymbol{p})$, according to the chosen mode of deformation (Eq. (17)). Thus, the cell center of mass is not much perturbed during this period. However, the contraction phase involves the whole cell body, which is pushed forward, then the velocity of the cell center of mass increases.

Second, by plotting the velocity of the center of mass of the pseudopod selected to migrate (Fig. 9a), it is possible to observe that the exact opposite situation takes place. In fact, the velocity is larger during the protrusion phase $(\sim 11.4 \mu \mathrm{m} / \mathrm{min}$, blue line Fig. 9a), while it decreases to $2.4 \mu \mathrm{m} / \mathrm{min}$ during the contraction phase (green line Fig. 9a) since the pseudopod adheres to the underneath substrate.

Finally, experimental observations (Lämmermann and Sixt 2009; Lauffenburger and Horwitz 1996) and previous computational models (Allena and Aubry 2012; Zaman et al. 2005) have shown that the migration process as well as the velocity of the cell are enhanced if a spatial asymmetry between the frontal and the rear adhesion regions exists (i.e., rear adhesion surface smaller with respect to the frontal one). Here, the frontal region coincides with the contact surface between the pseudopod and the substrate, which is smaller $\left(5.5 \mu \mathrm{m}^{2}\right)$ than the rear adhesion surface $\left(25 \mu \mathrm{m}^{2}\right)$. Thus, the asymmetry is inversed. In order to reestablish the correct spatial asymmetry, the rear boundary should be reduced to very few square microns, which could lead to slipping effects during the protrusion phase as discussed in Allena and Aubry (2012). 

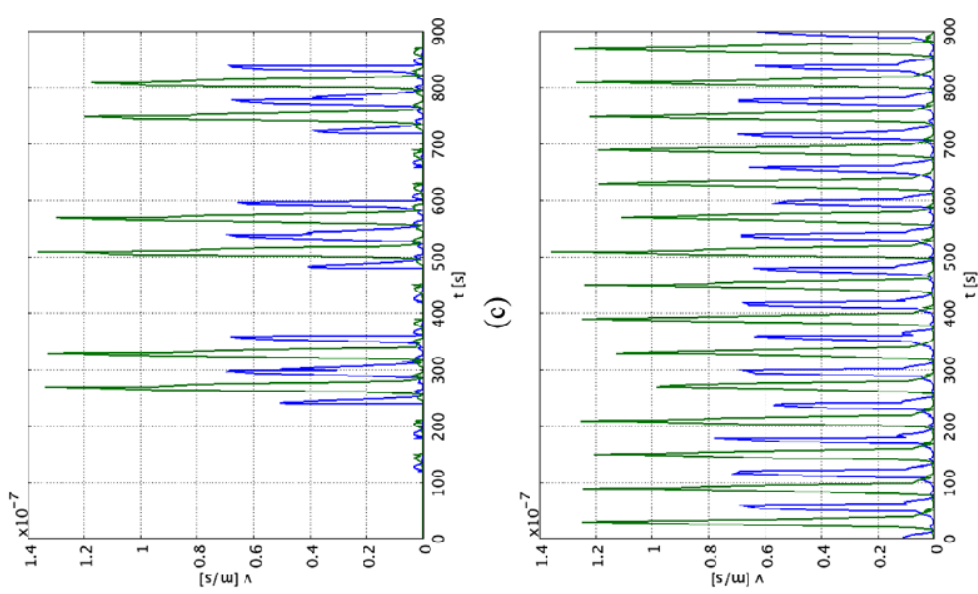

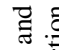

$\cong$

赵

항

छั

\%

政

픙

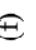

을

()ㅠㅇ

可

อิ

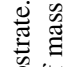

色

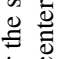

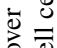
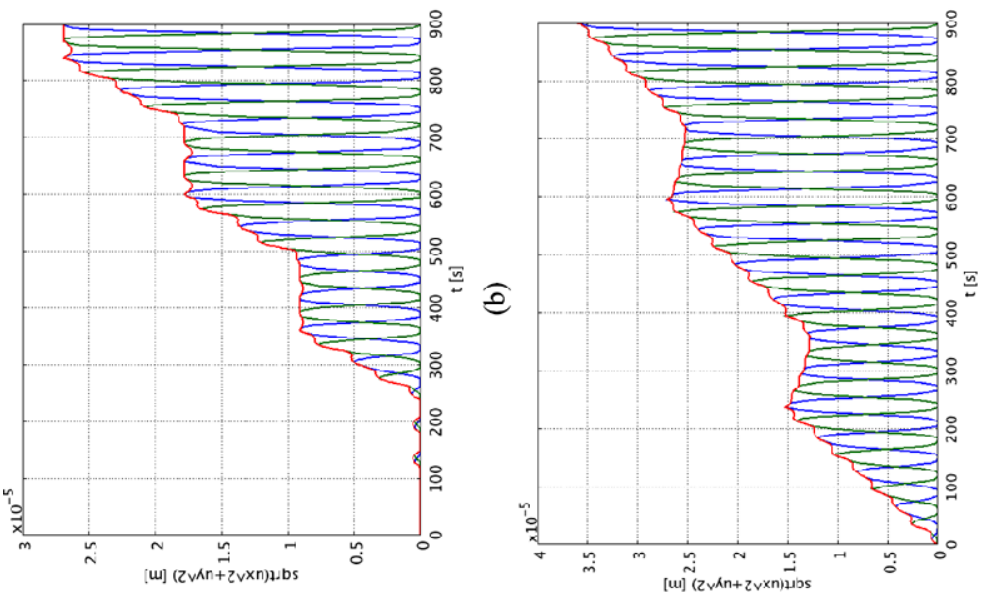

过

త⿹

잉

항 홍

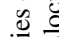

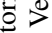

.9

政

อิ

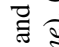

สิ

के

के

ఏ)

.

总

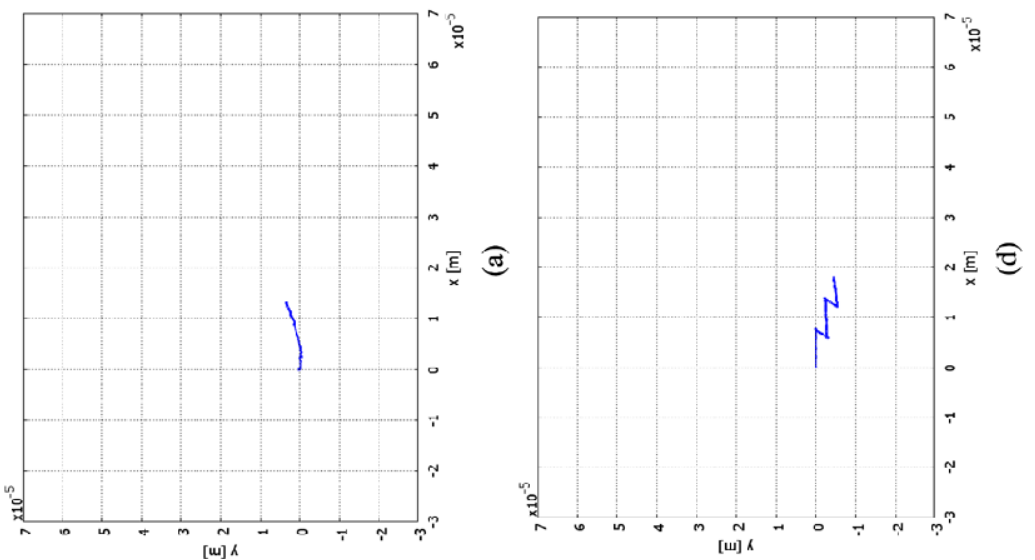

40

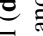

栗

की

ฐ

奈

.

बi

⿶.

잉

g

을

훙

을 


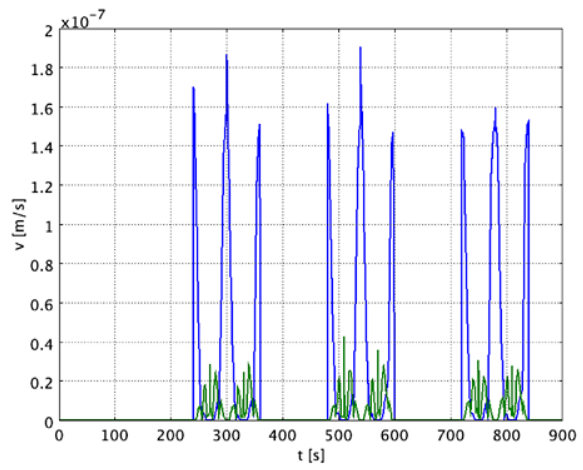

(a)

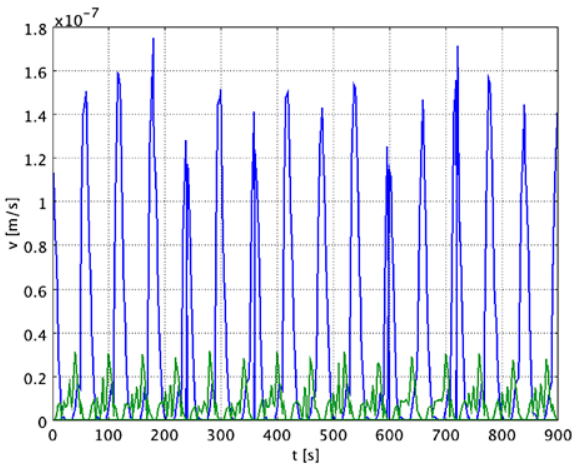

(b)

Fig. 9 Velocity of the center of mass of the pseudopod selected to migrate in the temporal (a) and the spatial (b) sensing model during the protrusion (blue line) and the contraction (green line) phase (Color figure online)

\subsubsection{Spatial Sensing Model}

In the spatial sensing model, the cell "sniffs" the environment at different points of the cell membrane and then only protrudes one pseudopod in the direction of the most attractive source (Eq. (20)), so that $\theta_{i}=\theta_{\text {source, } i \text { max }}$. This is possible because the actin filaments that trigger the initiation of the false feet are distributed toward the membrane along the whole cell perimeter, thus each particle of this region is "potentially" active.

To describe this strategy of migration, three external sources have been introduced in the system. Their directions have been fixed equal to $\theta_{\text {source, } 1}=0, \theta_{\text {source }, 2}=\frac{2 \pi}{3}$ and $\theta_{\text {source, } 3}=\frac{4 \pi}{3}$ while their intensities $\tau_{\text {source, } 1}(t), \tau_{\text {source }, 2}(t), \tau_{\text {source, } 3}(t)$ vary with respect to time (Fig. 7b).

In Movie 2, it is possible to observe the different phases of the migration and in Fig. 8d the trajectory of the cell center of mass over the substrate. The cell moves toward the first source $\left(\theta_{\text {source, } 1}=0\right)$ between 0-240 s, 360-600 s, and 720-900 s, while it migrates toward the second source $\left(\theta_{\text {source, } 3}=\frac{4 \pi}{3}\right.$ ) between $240-360 \mathrm{~s}$ and 600-720 s (Fig. 8e). The cell covers a distance of about $37 \mu \mathrm{m}$, which is larger than the distance covered for the temporal sensing model (Fig. 8e). This is due to the fact that in the spatial sensing model no steady active phases occur and there are no conditions to be satisfied. The cell in fact does not lose time, but always moves by protruding one pseudopod in the direction $\theta_{\text {source, } i \text { max }}$ of the most attractive source at that precise instant. Therefore, the velocity of the cell center of mass is always around some microns per minute in agreement with the literature (Adachi et al. 2009; Okeyo et al. 2009; Wilson et al. 2010), and similarly to the temporal sensing model, it is larger during the contraction $(\sim 7.8 \mu \mathrm{m} / \mathrm{min}$, green line Fig. $8 \mathrm{f})$ than the protrusion ( $\sim 4.8 \mu \mathrm{m} / \mathrm{min}$, blue line Fig. $8 \mathrm{f}$ ). Similar remarks to the temporal sensing model to explain the difference in velocity between the protrusion and the contraction phases may be done. Additionally, Fig. 9b shows the velocity of the center of mass of the pseudopod selected to migrate. In this case, the velocity is actually larger during the 
protrusion phase $(\sim 10.5 \mu \mathrm{m} / \mathrm{min}$, blue line Fig. $9 \mathrm{~b})$ and much smaller $(\sim 2.3 \mu \mathrm{m} / \mathrm{min}$, green line Fig. 9b) during the contraction phase.

\section{Conclusions}

In this paper, a $3 \mathrm{D}$ continuum model to simulate cell migration on $2 \mathrm{D}$ substrate in presence of multiple pseudopodia has been presented. As in a previous work (Allena and Aubry 2012), the present model focuses on the mechanical principles regulating the biological phenomenon, specifically the synchronization between the active deformations (protrusion-contraction) of the cell and the adhesion forces necessary to move forward on the underneath substrate. Although the mechanical and numerical formulations are very similar to the ones employed in Allena and Aubry (2012), here the pulsating movement of the cell is controlled by the formation of multiple pseudopodia at different sites of the cell membrane. The main characteristics (Van Haastert 2010) of the false feet are taken into account and reproduced by the model: (i) external signals such as chemoattractants initiate the formation of the pseudopodia, (ii) the cell always forms pseudopodia perpendicular to the membrane, (iii) there has to be a minimal distance of $\frac{\pi}{36}$ between two pseudopodia, (iv) pseudopodia are formed de novo in random directions and in regions of the cell that could be previously inactive, and (v) to migrate, the cell only uses one pseudopod.

In the first part of the paper (Sects. 2.3 and 4.1), the ability of the cell to protrude several pseudopodia (up to 8) in a steady configuration has been explored. In particular, three types of active strains (protrusion) have been tested, which allow reproducing various kinds of pseudopodia (lamellipodia, filipodia, etc.) and, therefore, the behavior of various cells. Furthermore, since rarely the cell presents a perfect symmetric morphology, randomness has been introduced in the model to control both the direction and the amplitude of the pseudopodia (Sect. 4.2).

In the second part of the paper (Sects. 3 and 4.3), the migration process is described. As previously mentioned, the cell only uses one pseudopod to move forward, thus two approaches may be adopted: the temporal (Gerish et al. 1974) or the spatial (Zigmond et al. 1981) sensing model. In the temporal sensing model (Sects. 3.1 and 4.3.1), the cell simultaneously initiates several pseudopodia at different spots of the membrane. Then it chooses the one which is the best oriented toward the external source to migrate and retracts the others.

In the spatial sensing model instead (Sects. 3.2 and 4.3.2), the cell only protrudes one pseudopod in the direction of the most attractive source and uses it to move.

While in the first approach the cell behaves as if it was "blind," and spies on the environment with multiple false feet and later selects the right one, in the second approach, the cell seems to see from far away the external source and it therefore does not lose too much energy and only forms one pseudopod, which is already oriented in the direction of the attractant. These two techniques show two distinct behaviors of the cell very similar to the ones described in the previous paper (Allena and Aubry 2012), where the cell avoided the "obstacles" on the substrate by adopting the "runand-tumble" or the "look-and-run" approach. 
The new model allows having a more realistic representation of the migration process, although there are still further improvements that may be done. First, a more proper description of the cell structure including, for instance, the nucleus and the actin filaments should be used with specific mechanical properties. Second, as already proposed in Allena et al. (2011), a diffusion-reaction equation should be implemented in order to regulate the active strains (protrusion and contraction) that are now directly introduced into the mechanical formulation. Third, the migration process should be reproduced in a $3 \mathrm{D}$ environment constituted by more or less dense network of fibers that trigger then the direction of the cell.

Acknowledgements I am grateful to Professor Denis Aubry for discussions and critical comments on the manuscript, and to A. Stéphanou for the permission to use experimental figures.

\section{Appendix A: Heaviside and Level Set Functions}

Let $h(\psi)$ be the classical Heaviside function defined as

$$
h(\psi)= \begin{cases}1 & \psi>0 \\ 0 & \text { otherwise }\end{cases}
$$

and $l(\phi)$ the level set function which reads

$$
l(\phi)=c
$$

where $\psi$ is a real variable, $\phi$ is a set of real variables and $c$ is a constant value.

Then, by composing the Heaviside and the level set function, three different applications are obtained as follows:

$$
\begin{aligned}
& \Omega_{i}(\boldsymbol{p})=h \circ l_{i}(\boldsymbol{p}) \\
& \mathrm{T}_{i}(t)=h \circ l_{i}(t) \\
& \Theta_{i}(\theta)=h \circ l_{i}(\theta)
\end{aligned}
$$

which allow to determine whether a spatial particle with initial position $\boldsymbol{p}$, a time instant $t$ or an angle $\theta$ belong or not to a geometrical domain, a time interval or a range of directions, respectively.

\section{Appendix B: Geometrical Level Set Functions}

The annulus describing the actin network is defined by a characteristic function as follows:

$$
l_{\text {annulus }}(\boldsymbol{p})=\|\boldsymbol{p}\|^{2}-r_{\text {annulus }}^{2}
$$

The cone of action is defined by

$$
l_{\text {cone }, i}(\boldsymbol{p})=\left\|\boldsymbol{p}_{s, i}-p_{d, i} \boldsymbol{n}_{0, i}\right\|-\operatorname{tg}(\varphi) p_{d, i}
$$

where $p_{d, i}$ is the horizontal distance of a particle $\boldsymbol{p}_{s, i}=\left(p_{x}, p_{y}, 0\right)$ of the pseudopod $i$ from $\boldsymbol{p}_{c s}=\left(p_{c x}, p_{c y}, 0\right)$ (Fig. 1c), which is the projection of the cell center of mass 
$\boldsymbol{p}_{c}$ on the $x, y$ plane along the axis of the pseudopod $\boldsymbol{n}_{0, i}$ (Fig. 1c). Thus, $p_{d, i}$ is given by

$$
p_{d, i}=\left(\boldsymbol{p}_{s}-\boldsymbol{p}_{c s}, \boldsymbol{n}_{0, i}\right)
$$

where $\boldsymbol{n}_{0, i}$, which is always perpendicular to the cell membrane (Sect. 1.1), reads

$$
\boldsymbol{n}_{0, i}=\cos \theta_{i}(t) \mathbf{i}_{x}+\sin \theta_{i}(t) \mathbf{i}_{y}
$$

with $\theta_{i}$ the angle of the pseudopod $i$.

\section{Appendix C: Temporal Level Set Functions}

The level set function $l_{p}(t)$ and $l_{c}(t)$ for the protrusion and the contraction phase are defined as follows:

$$
\begin{aligned}
& l_{p}(t)=\sin \left(2 \pi \frac{t}{T_{\text {migr }}}\right) \\
& l_{c}(t)=-\sin \left(2 \pi \frac{t}{T_{\text {migr }}}\right)
\end{aligned}
$$

\section{Appendix D: Temporal Sensing Model Level Set Functions}

In order for the cell to be able to simultaneously extend multiple pseudopodia, three criteria need to be satisfied (Sect. 3.1). Each one of them is expressed through a specific analytical function $\Theta_{i}(\theta)=h \circ l_{i}(\theta)$ and allows determining the admissibility of the angle $\theta_{i}$ of each pseudopod. Here, the level set functions associated to each criterion are defined.

Let $\theta_{i}$ being the direction of a pseudopod $i$ and $\theta_{i+1}$ and $\theta_{i-1}$ the directions of its anticlockwise and clockwise nearest pseudopod, then $l_{\text {crit } 1, i}\left(\theta_{i}\right)$ reads

$$
l_{\text {crit } 1, i}\left(\theta_{i}\right)=\left\{\begin{array}{l}
\theta_{i}-\left(\theta_{i+1}+\frac{\pi}{36}\right) \\
-\theta_{i}+\left(\theta_{i+1}-\frac{\pi}{36}\right) \\
\theta_{i}-\left(\theta_{i-1}+\frac{\pi}{36}\right) \\
-\theta_{i}+\left(\theta_{i-1}-\frac{\pi}{36}\right)
\end{array}\right.
$$

To contract and migrate, the cell must choose the pseudopod which is the best oriented in the direction $\theta_{\text {source, } i}$, thus $\Theta_{\text {crit } 2, i}\left(\theta_{i}\right)$ need to be verified. The associated level set function $l_{\mathrm{crit} 2, i}\left(\theta_{i}\right)$ reads

$$
l_{\text {crit } 2, i}\left(\theta_{i}\right)=\left\{\begin{array}{l}
-\left|\theta_{i}-\theta_{\text {source }, i}\right|+\left|\theta_{i+1}-\theta_{\text {source }, i}\right| \\
-\left|\theta_{i}-\theta_{\text {source }, i}\right|+\left|\theta_{i-1}-\theta_{\text {source }, i}\right|
\end{array}\right.
$$

Finally, the angle $\theta_{i}$ of the pseudopod $\Omega_{\text {ppod, } i}$ chosen to migrate has to be in the same quadrant of $\theta_{\text {source, } i}$. Thus, $\Theta_{\text {crit } 3, i}\left(\theta_{i}\right)$ is implemented in the model and the associated 
level set function $l_{\text {crit } 3, i}\left(\theta_{i}\right)$ is defined as

$$
l_{\text {crit } 3, i}\left(\theta_{i}\right)= \begin{cases}\theta_{i} & \text { if } 0<\theta_{\text {source }, i}<\frac{\pi}{2} \\ -\theta_{i}+\frac{\pi}{2} & \text { if } 0<\theta_{\text {source }, i}<\frac{\pi}{2} \\ \theta_{i}-\frac{\pi}{2} & \text { if } \frac{\pi}{2}<\theta_{\text {source }, i}<\pi \\ -\theta_{i}+\pi & \text { if } \frac{\pi}{2}<\theta_{\text {source }, i}<\pi \\ \theta_{i}-\pi & \text { if } \pi<\theta_{\text {source }, i}<\frac{3 \pi}{2} \\ -\theta_{i}+\frac{3 \pi}{2} & \text { if } \pi<\theta_{\text {source }, i}<\frac{3 \pi}{2} \\ \theta_{i}-\frac{3 \pi}{2} & \text { if } \frac{3 \pi}{2}<\theta_{\text {source }, i}<2 \pi \\ -\theta_{i}+2 \pi & \text { if } \frac{3 \pi}{2}<\theta_{\text {source }, i}<2 \pi\end{cases}
$$

\section{Appendix E: Adhesion Surfaces and Forces}

Similarly to the pseudopod domain $\Omega_{\text {ppod, } i}(p)$, the frontal adhesion surface results from the intersection between the annulus and the cone at $z=0$. Thus, $l_{\text {annulus }}\left(\boldsymbol{p}_{s}\right)$ and $l_{\text {cone }, i}\left(\boldsymbol{p}_{S}\right)$ are now expressed as follows:

$$
\begin{aligned}
& l_{\text {annulus }}\left(\boldsymbol{p}_{s}\right)=\left\|\boldsymbol{p}_{s}\right\|^{2}-r_{\text {annulus }}^{2} \\
& l_{\text {cone }, i}\left(\boldsymbol{p}_{s}\right)=\left\|\boldsymbol{p}_{s, i}-p_{d, i} \boldsymbol{n}_{0, i}\right\|-\operatorname{tg}(\varphi) p_{d, i}
\end{aligned}
$$

The level set function $l_{r, i}\left(\boldsymbol{p}_{s}\right)$, which allows defining the rear adhesion surface $\partial \Omega_{r, i}\left(\boldsymbol{p}_{s}\right)$, reads

$$
l_{r, i}\left(\boldsymbol{p}_{s}\right)=-\left(\boldsymbol{p}_{s}-\boldsymbol{p}_{c s}, \boldsymbol{n}_{0, i}\right)-l_{r}(24)
$$

where $l_{r}$ is the distance of $\boldsymbol{p}_{c s}$ from the boundary of the rear adhesion surface and is here equal to $2 \mu \mathrm{m}$ (Fig. 1c).

The level set functions $l_{a f}(t)$ and $l_{a r}(t)$, which synchronize the adhesion forces with the active deformations (Sect. 3.3), are expressed as

$$
\begin{aligned}
& l_{a f}(t)=-\frac{\partial\left(\sin \left(2 \pi \frac{t}{T_{\text {migr }}}\right)\right)}{\partial t} \\
& l_{a r}(t)=\frac{\partial\left(\sin \left(2 \pi \frac{t}{T_{\text {migr }}}\right)\right)}{\partial t}
\end{aligned}
$$

\section{Appendix F: Sensitivity Analysis}

The high number of parameters in the model (20, Table 1$)$ does not allow performing an exhaustive sensitivity study. Nevertheless, the parameters can be classified in four categories:

(1) the parameters referenced in the literature: $E_{s}$ (Laurent et al. 2005), $\mu_{f v}$ (Bausch et al. 1999; Drury and Dembo 2001), $\rho$ (Fukui et al. 2000), $T_{\text {migr }}$ (Allena and Aubry 2012; Dong et al. 2002), and the minimal distance between the pseudopodia $\left( \pm \frac{\pi}{36}\right)$ (Bosgraaf and Van Haastert 2009a); 


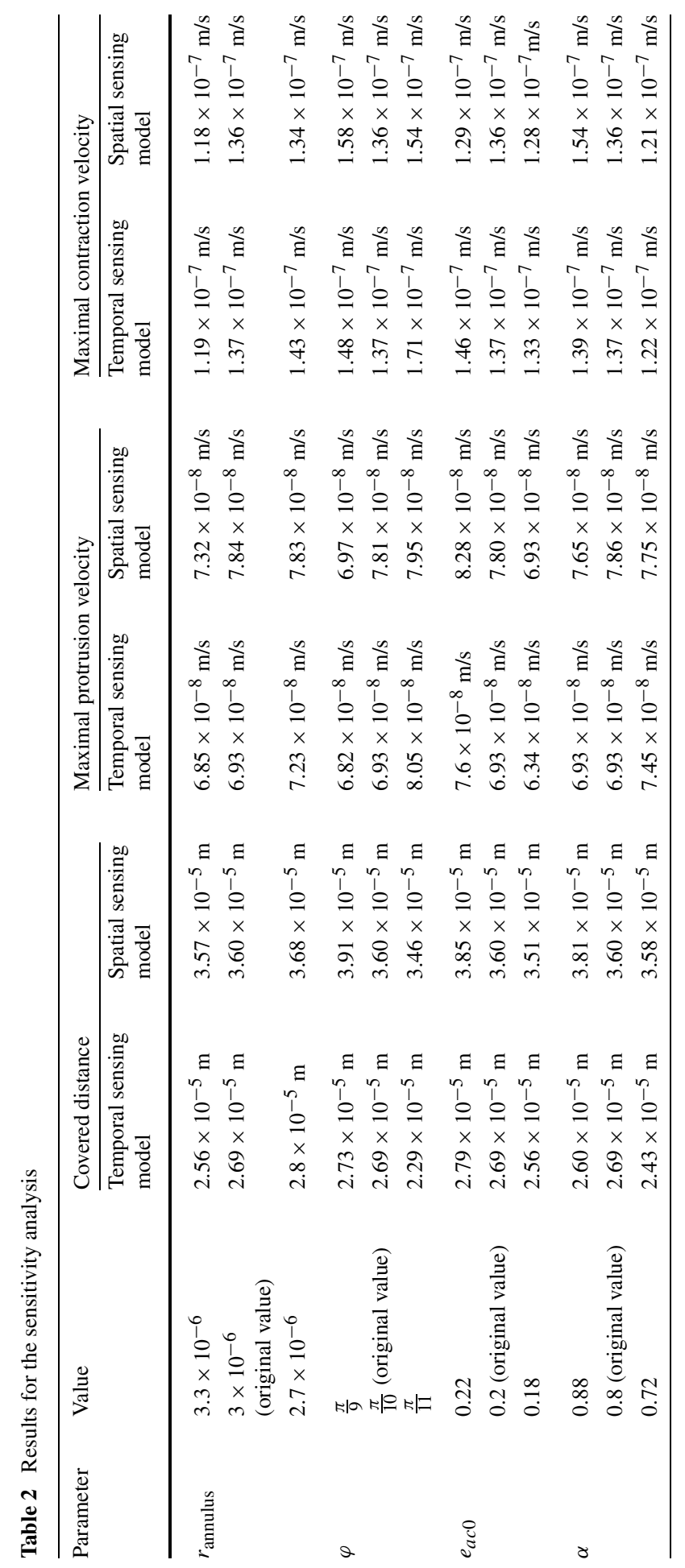


(2) the parameters that have been chosen within a reasonable physical range (Allena and Aubry 2012): $r, E_{f e}, v_{s}, v_{f}$;

(3) the parameters that have been arbitrarily chosen and for which a sensitivity analysis has been proposed in Allena and Aubry (2012), showing a slight influence on the final results: $h, e_{a p 0}, \partial \Omega_{r, i}, \mu_{f f}, \mu_{f r}$;

(4) the parameters that have been arbitrarily chosen and for which a sensitivity analysis is proposed here: $r_{\text {annulus }}, \varphi, e_{a c 0}, \alpha$.

Each parameter has been allowed a variance of $\pm 10 \%$ in both the temporal and the spatial sensing models. The values of the source directions $\theta_{\text {source, } i}$ are assumed to not affect the mechanical behavior of the cell, but just the path over the $2 \mathrm{D}$ substrate in both the temporal and spatial sensing models.

As a general remark, for both the temporal and the spatial sensing models, the variation of the parameters do not highly affect the final results in terms of the covered distance and maximal velocities of the cell center of inertia during the protrusion and contraction phase (Table 2). More importantly, such a variation does not affect the fundamental principles of the mechanical model. Nevertheless, we can notice that higher values of the cone apex angle $\varphi$, the cyclic active contraction $e_{a c 0}$, the gradient amplitude $\alpha$, as expected, enhance the movement forward in both the temporal and the spatial sensing models, thus the cell is able to migrate over a longer distance. On the contrary, a higher value of $r_{\text {annulus }}$, which reduces the volume of the actin network and, therefore, the volume of the pseudopod also (Eq. (32)) leads to a smaller covered distance.

\section{References}

Adachi, T., Okeyo, K. O., Shitagawa, Y., \& Hojo, M. (2009). Strain field in actin filament network in lamellipodia of migrating cells: implication for network reorganization. J. Biomech., 42, 297-302.

Allena, R., \& Aubry, D. (2012). "Run-and-tumble" or "look-and-run"? A mechanical model to explore the behavior of a migrating amoeboid cell. J. Theor. Biol., 306, 15-31.

Allena, R., Mouronval, A.-S., \& Aubry, D. (2010). Simulation of multiple morphogenetic movements in the Drosophila embryo by a single 3D finite element model. J. Mech. Behav. Biomed. Mater., 3, 313-323.

Allena, R., Muñoz, J. J., \& Aubry, D. (2011). Diffusion-reaction model for Drosophila embryo development. Comput. Methods Biomech. Biomed. Eng. doi:10.1080/10255842.2011.616944.

Alt, W. (1990). Mathematical models and analysing methods for the lamellipodial activity of leukocytes. In N. Akkas (Ed.), Nato ASI series H: Vol. 42. Biomechanics of active movement and deformation of cells (pp. 403-422).

Alt, W., \& Tranquillo, R. T. (1995). Basic morphogenetic system modeling shape changes of migrating cells: How to explain fluctuating lamellipodial dynamics. J. Biol. Syst., 3, 905-916.

Andrew, N., \& Insall, R. H. (2007). Chemotaxis in shallow gradients is mediated independently of PtdIns 3-kinase by biased choices between random protrusions. Nat. Cell Biol., 9, 193-200.

Arrieumerlou, C., \& Meyer, T. (2005). A local coupling model and compass parameter for eukaryotic chemotaxis. Dev. Cell, 8, 215-227.

Bahat, A., \& Eisenbach, M. (2006). Sperm Thermotaxis. Mol. Cell. Endocrinol., 252, 115-119.

Balan, C., \& Tsakmakis, C. (2002). A finite deformation formulation of the 3-parameter viscoelastic fluid. J. Non-Newton. Fluid Mech., 103, 45-64.

Bausch, A. R., Möller, W., \& Sackmann, E. (1999). Measurement of local viscoelasticity and forces in living cells by magnetic tweezers. Biophys. J., 76, 573-579.

Bereiter-Hahn, J., \& Lüers, H. (1998). Subcellular tension fields and mechanical resistance of the lamella front related to the direction of locomotion. Cell Biochem. Biophys., 29, 243-262. 
Bonet, J. (2001). Large strain viscoelastic constitutive models. Int. J. Solids Struct., 38, 2953-2968.

Borisy, G. G., \& Svitkina, T. M. (2000). Acting machinery: pushing the envelope. Curr. Opin. Cell Biol., $12,104-112$.

Bosgraaf, L., \& Van Haastert, P. J. M. (2009a). Navigation of chemotactic cells by parallel signaling to pseudopod persistence and orientation. PLOS ONE, 4, e6842.

Bosgraaf, L., \& Van Haastert, P. J. M. (2009b). The ordered extension of pseudopodia by amoeboid cells in the absence of external cues. PLoS ONE, 4, e5253.

Bottino, D., Mogilner, A., Roberts, T., Stewart, M., \& Oster, G. (2002). How nematode sperm crawl. J. Cell Sci., 115, 367-384.

Carlier, M. F., \& Pantaloni, D. (1997). Control of actin dynamics in cell motility. J. Mol. Biol., 269, 459467.

Carlsson, A. E., \& Sept, D. (2008). Mathematical modeling of cell migration. Methods Cell Biol., 84, 911-937.

Condeelis, J. (1993). Life at the leading edge: the formation of cell protrusions. Annu. Rev. Cell Biol., 9 , 411-444.

Cramer, L. P., Siebert, M., \& Mitchison, T. J. (1997). Identification of novel graded polarity actin filament bundles in locomoting heart fibroblasts: implications for the generation of motile force. J. Cell Biol., 136, 1287-1305.

Dong, C., Slattery, M. J., Rank, B. M., \& You, J. (2002). In vitro characterization and micromechanics of tumor cell chemotactic protrusion, locomotion, and extravasation. Ann. Biomed. Eng., 30, 344-355.

Drury, J. L., \& Dembo, M. (2001). Aspiration of human neutrophils: effects of shear thinning and cortical dissipation. Biophys. J., 81, 3166-3177.

Flaherty, B., McGarry, J. P., \& McHugh, P. E. (2007). Mathematical models of cell motility. Cell Biochem. Biophys., 49, 14-28.

Franca-Koh, J., Kamimura, Y., \& Devreotes, P. (2006). Navigating signaling networks: chemotaxis in Dictyostelium discoideum. Curr. Opin. Genet. Dev., 16, 333-338.

Friedl, P., \& Gilmour, D. (2009). Collective cell migration in morphogenesis, regeneration and cancer. Nat. Rev. Mol. Cell Biol., 10, 445-457.

Fukui, Y., Uyeda, T. Q. P., Kitayama, C., \& Inoué, S. (2000). How well can an amoeba climb? Proc. Natl. Acad. Sci. USA, 97, 10020-10025.

Gail, M. H., \& Boone, C. W. (1970). The locomotion of mouse fibroblasts in tissue culture. Biophys. J., 10, 980-993.

Gerish, G., Malchow, D., \& Hess, B. (1974). Cell communication and cyclic-amp regulation during aggregation of the slime mold, dictyostelium discoideum. In L. Jaenicke (Ed.), Biochemistry of sensory functions (pp. 279-298). New York: Springer.

Gracheva, M. E., \& Othmer, H. G. (2004). A continuum model of motility in ameboid cells. Bull. Math. Biol., 66, 167-193.

Hoeller, O., \& Kay, R. R. (2007). Chemotaxis in the absence of PIP3 gradients. Curr. Biol., 17, 813-817.

Holzapfel, G. A. (2000). Nonlinear solid mechanics: a continuum approach for engineering (1st ed.). New York: Wiley.

Insall, R. H. (2010). Understanding eukaryotic chemotaxis: a pseudopod-centred view. Nat. Rev. Mol. Cell Biol., 11, 453-458.

Jay, P. Y., Pham, P. A., Wong, S. A., \& Elson, E. L. (1995). A mechanical function of myosin II in cell motility. J. Cell Sci., 108, 387-393.

Karsenti, E. (2008). Self-organization in cell biology: a brief history. Nat. Rev. Mol. Cell Biol., 9, $255-262$.

Killich, T., et al. (1993). The locomotion, shape and pseudopodial dynamics of unstimulated Dictyostelium cells are not random. J. Cell Sci., 106(Pt 4), 1005-1013.

King, J. S., \& Insall, R. H. (2009). Chemotaxis: finding the way forward with Dictyostelium. Trends Cell Biol., 19, 523-530.

Lämmermann, T., \& Sixt, M. (2009). Mechanical modes of "amoeboid" cell migration. Curr. Opin. Cell Biol., 21, 636-644.

Larson, R. G. (1998). The structure and rheology of complex fluids. Oxford: Oxford University Press.

Lauffenburger, D. A., \& Horwitz, A. F. (1996). Cell migration: a physically integrated molecular process. Cell, 84, 359-369.

Laurent, V. M., et al. (2005). Gradient of rigidity in the lamellipodia of migrating cells revealed by atomic force microscopy. Biophys. J., 89, 667-675.

Lee, J., Ishihara, A., \& Jacobson, K. (1993). How do cells move along surfaces? Trends Cell Biol., 3, 366-370. 
Li, L., Nørrelykke, S. F., \& Cox, E. C. (2008). Persistent cell motion in the absence of external signals: a search strategy for eukaryotic cells. PLoS ONE, 3, e2093.

Lim, C. T., Zhou, E. H., \& Quek, S. T. (2006). Mechanical models for living cells-a review. J. Biomech., $39,195-216$.

Lubarda, V. (2004). Constitutive theories based on the multiplicative decomposition of deformation gradient: thermoelasticity, elastoplasticity, and biomechanics. Appl. Mech. Rev., 57, 95-109.

Merkel, R., et al. (2000). A micromechanic study of cell polarity and plasma membrane cell body coupling in Dictyostelium. Biophys. J., 79, 707-719.

Merlot, S., \& Firtel, R. A. (2003). Leading the way: directional sensing through phosphatidylinositol 3kinase and other signaling pathways. J. Cell Sci., 116, 3471-3478.

Mogilner, A., \& Oster, G. (1996). The physics of lamellipodial protrusion. Eur. Biophys. J., 25, 47-53.

Mogilner, A., \& Rubinstein, B. (2005). The physics of filopodial protrusion. Biophys. J., 89, 782-795.

Mogilner, A., \& Verzi, D. W. (2003). A simple 1-D physical model for the crawling nematode sperm cell. J. Stat. Phys., 110, 1169-1189.

Muñoz, J. J., Barrett, K., \& Miodownik, M. (2007). A deformation gradient decomposition method for the analysis of the mechanics of morphogenesis. J. Biomech., 40, 1372-1380.

Murray, J. D. (2003). Mathematical biology II: spatial models and biomedical applications. Berlin: Springer.

Okeyo, K. O., Adachi, T., Sunaga, J., \& Hojo, M. (2009). Actomyosin contractility spatiotemporally regulates actin network dynamics in migrating cells. J. Biomech., 42, 2540-2548.

Oster, G. F. (1984). On the crawling of cells. J. Embryol. Exp. Morphol., 83, 329-364.

Oster, G. F., \& Perelson, A. S. (1987). The physics of cell motility. J. Cell Sci., Suppl., 8, 35-54.

Patlak, C. (1953). Random walk with persistence and external bias. Bull. Math. Biol., 15, 311-338.

Phillipson, M., et al. (2006). Intraluminal crawling of neutrophils to emigration sites: a molecularly distinct process from adhesion in the recruitment cascade. J. Exp. Med., 203, 2569-2575.

Potel, M. J., \& Mackay, S. A. (1979). Preaggregative cell motion in Dictyostelium. J. Cell Sci., 36, 281309.

Rubinstein, B., Jacobson, K., \& Mogilner, A. (2005). Multiscale two-dimensional modeling of a motile simple-shaped cell. Multiscale Model. Simul., 3, 413-439.

Sakamoto, Y., Prudhomme, S., \& Zaman, M. H. (2011). Viscoelastic gel-strip model for the simulation of migrating cells. Ann. Biomed. Eng., 39, 2735-2749.

Schaub, S., Bohnet, S., Laurent, V. M., Meister, J.-J., \& Verkhovsky, A. B. (2007). Comparative maps of motion and assembly of filamentous actin and myosin II in migrating cells. Mol. Biol. Cell, 18, 3723-3732.

Schneider, I. C., \& Haugh, J. M. (2006). Mechanisms of gradient sensing and chemotaxis: conserved pathways, diverse regulation. Cell Cycle, 5, 1130-1134.

Small, J. V., Rohlfs, A., \& Mogilner, A. (1993). In G. Jones, C. Wigley, \& R. Warn (Eds.), Actin and cell movement. Cell behaviour: adhesion and motility (pp. 57-71). London: The Society of Experimental Biology.

Stéphanou, A., Chaplain, M. A. J., \& Tracqui, P. (2004). A mathematical model for the dynamics of large membrane deformations of isolated fibroblasts. Bull. Math. Biol., 66, 1119-1154.

Stolarska, M. A., Kim, Y., \& Othmer, H. G. (2009). Multi-scale models of cell and tissue dynamics. Philos. Trans. R. Soc., Math. Phys. Eng. Sci., 367, 3525-3553.

Taber, L. A. (2004). Nonlinear theory of elasticity: applications in biomechanics. Singapore: World Scientific.

Taber, L. A., Shi, Y., Yang, L., \& Bayly, P. V. (2011). A poroelastic model for cell crawling including mechanical coupling between cytoskeletal contraction and actin polymerization. J. Mech. Mater. Struct., 6, 569-589.

Takagi, H., Sato, M. J., Yanagida, T., \& Ueda, M. (2008). Functional analysis of spontaneous cell movement under different physiological conditions. PLOS ONE, 3, e2648.

Theriot, J. A., \& Mitchison, T. J. (1991). Actin microfilament dynamics in locomoting cells. Nature, 352, $126-131$.

Van Haastert, P. J. M. (2010). Chemotaxis: insights from the extending pseudopod. J. Cell Sci., 123, 30313037.

Van Haastert, P. J. M., \& Bosgraaf, L. (2009). The local cell curvature guides pseudopodia towards chemoattractants. HFSP J., 3, 282-286.

Veksler, A., \& Gov, N. S. (2007). Phase transitions of the coupled membrane-cytoskeleton modify cellular shape. Biophys. J., 93, 3798-3810. 
Weijer, C. J. (2009). Collective cell migration in development. J. Cell Sci., 122, 3215-3223.

Weiner, O. D. (2002). Regulation of cell polarity during eukaryotic chemotaxis: the chemotactic compass. Curr. Opin. Cell Biol., 14, 196-202.

Wilson, C. A., et al. (2010). Myosin II contributes to cell-scale actin network treadmilling through network disassembly. Nature, 465, 373-377.

Young, J., \& Mitran, S. (2010). A numerical model of cellular blebbing: a volume-conserving, fluidstructure interaction model of the entire cell. J. Biomech., 43, 210-220.

Zaman, M. H., Kamm, R. D., Matsudaira, P., \& Lauffenburger, D. A. (2005). Computational model for cell migration in three-dimensional matrices. Biophys. J., 89, 1389-1397.

Zhao, M. (2009). Electrical fields in wound healing - an overriding signal that directs cell migration. Semin. Cell Dev. Biol., 20, 674-682.

Zhu, C., \& Skalak, R. (1988). A continuum model of protrusion of pseudopod in leukocytes. Biophys. J., 54, 1115-1137.

Zigmond, S. H., Levitsky, H. I., \& Kreel, B. J. (1981). Cell polarity: an examination of its behavioral expression and its consequences for polymorphonuclear leukocyte chemotaxis. J. Cell Biol., 89, 585592. 